Award Number: W81XWH-07-1-0238

TITLE: The Infectious Pathogenesis of Prostate Cancer

PRINCIPAL INVESTIGATOR: Hans-Olov Adami, M.D., Ph.D. Lorelei Mucci, Sc.D.

CONTRACTING ORGANIZATION: Harvard School of Public Health Boston, MA 02115

REPORT DATE: April 2011

TYPE OF REPORT: Revised Final

PREPARED FOR: U.S. Army Medical Research and Materiel Command Fort Detrick, Maryland 21702-5012

DISTRIBUTION STATEMENT: Approved for Public Release;

Distribution Unlimited

The views, opinions and/or findings contained in this report are those of the author(s) and should not be construed as an official Department of the Army position, policy or decision unless so designated by other documentation. 


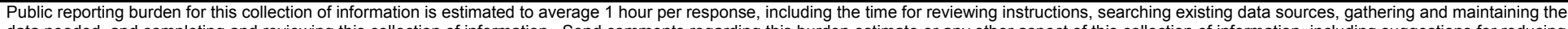

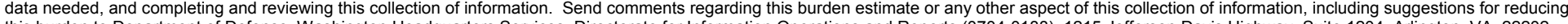

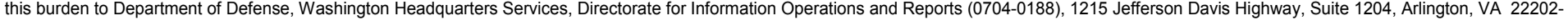

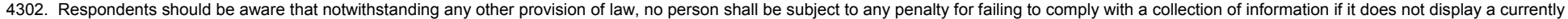
valid OMB control number. PLEASE DO NOT RETURN YOUR FORM TO THE ABOVE ADDRESS.

\begin{tabular}{|l|l|}
\hline 1. REPORT DATE & 2. REPORT TYPE \\
\hline
\end{tabular}

April 2011

4. TITLE AND SUBTITLE

Revised Final

The Infectious Pathogenesis of Prostate Cancer

\section{DATES COVERED}

15 Feb 2007 - 31 March 2011

5a. CONTRACT NUMBER

5b. GRANT NUMBER

W81XWH-07-1-0238

5c. PROGRAM ELEMENT NUMBER

5d. PROJECT NUMBER

5e. TASK NUMBER

5f. WORK UNIT NUMBER

8. PERFORMING ORGANIZATION REPORT NUMBER

10. SPONSOR/MONITOR'S ACRONYM(S)

\section{U.S. Army Medical Research and Materiel Command}

Fort Detrick, Maryland 21702-5012

11. SPONSOR/MONITOR'S REPORT NUMBER(S)

12. DISTRIBUTION I AVAILABILITY STATEMENT

Approved for Public Release; Distribution Unlimited

\section{SUPPLEMENTARY NOTES}

\section{ABSTRACT}

Accumulating evidence points to a role of chronic inflammation in the pathogenesis and progression of cancers, including prostate. Infections are important agents in the genesis of inflammation. For prostate cancer, several lines of evidence point to a role of infections as important agents, although no specific infection has consistently been identified. In this project, we are examining two specific infectious agents with respect to prostate cancer: $\mathrm{T}$ vaginalis, the most common non-viral sexually transmitted infection, and the recently identified retrovirus XMRV. The aims of this study are 1-) To assess the role of the newly identified XMRV virus in prostate carcinogenesis and progression; 2-) To characterize the role of the infectious protozoa T. vaginalis in prostate carcinogenesis and progression. The current study is nested within the Swedish Watchful Waiting Cohort, a population-based cohort of 1,256 Swedish men diagnosed with localized prostate cancer. During 28 years of follow-up, 320 men have died of cancer, and thus this is a powerful population in which to examine determinants of prostate cancer progression. A tumor repository from archival tissue specimens have been collected from all men in the cohort and will be used to assay for presence of the infections.

\section{SUBJECT TERMS}

Prostate cancer; cancer survival; infections; T vaginalis; XMRV

\begin{tabular}{|c|c|c|c|c|c|}
\hline \multicolumn{3}{|c|}{ 16. SECURITY CLASSIFICATION OF: } & \multirow{2}{*}{$\begin{array}{c}\text { 17. LIMITATION } \\
\text { OF ABSTRACT } \\
\text { UU }\end{array}$} & \multirow{2}{*}{$\begin{array}{l}\text { 18. NUMBER } \\
\text { OF PAGES } \\
\qquad 55\end{array}$} & \multirow{2}{*}{$\begin{array}{l}\text { 19a. NAME OF RESPONSIBLE PERSON } \\
\text { USAMRMC } \\
\text { 19b. TELEPHONE NUMBER (include area } \\
\text { code) }\end{array}$} \\
\hline $\begin{array}{r}\text { a. REPORT } \\
U\end{array}$ & $\begin{array}{c}\text { b. ABSTRACT } \\
U\end{array}$ & $\begin{array}{c}\text { c. THIS PAGE } \\
\text { U }\end{array}$ & & & \\
\hline
\end{tabular}




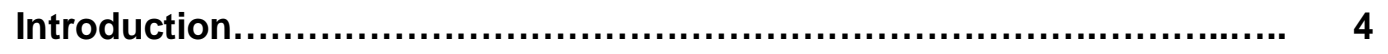

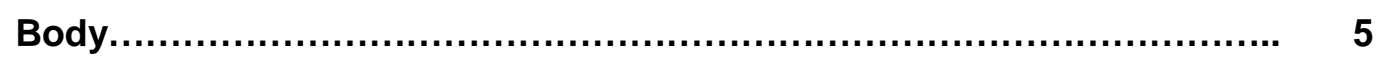

Key Research Accomplishments.......................................... 9

Reportable Outcomes...................................................... 10

Conclusion....................................................................... 12

References................................................................... 13

Supporting Data................................................................ 14

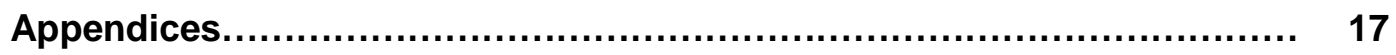




\section{INTRODUCTION}

Prostate cancer has considerable biologic heterogeneity, such that some men experience an aggressive course while many have a slow growing or indolent disease (1-3). Thus, central issues in prostate cancer research are to identify mechanisms which are amenable to prevention and treatment, and to understand pathways that lead to aggressive cancer. A growing body of epidemiologic, genetic and molecular pathological data points to the role of chronic inflammation in the pathogenesis and progression of prostate cancer (4). The pathways involved in chronic inflammation induce cellular damage and compensatory cellular proliferation (5). Clinical prostatitis, which occurs in approximately $9 \%$ of men between the ages of 40 and 79 , has been linked to prostate cancer in several epidemiologic studies (6). Moreover, surgical prostate tumor specimens often exhibit histological evidence of prostatitis, although the determinants of this prostatic inflammation are unclear. Perhaps of greater importance, data also suggests that the degree of inflammation may be a predictor of more aggressive disease. In a study of 161 men undergoing radical prostatectomy (7), 5-year recurrencefree survival was significantly lower among patients with high-grade inflammation in malignant tissue $(27 \%)$ than in patients with low-grade or no evidence of inflammation $(65 \%)$, independent of Gleason grade, preoperative PSA level, and pathologic stage. Infectious agents are likely targets involved in the initiation and exacerbation of chronic inflammation, and infections can lead to increased risk of several cancers (8). Indeed, an estimated $15 \%$ of malignancies globally are thought to have an infectious etiology (9, 10). Infectious agents may also have direct effects on carcinogenesis through the transformation of cells via incorporation of active oncogenes into the host genome, inhibition of tumor suppressors, stimulation of proliferation signals, or through immune suppression. Known oncogenic infections are typically highly prevalent within the host population, persistent within the host, and require a variety of co-factors for malignant transformation. Two papers $(11,12)$ provided evidence suggesting involvement of the newly identified murine-like retrovirus XMRV and the protozoan $T$. vaginalis in prostate cancer. The objective of the proposed study was to evaluate and extend the initial findings on $T$. vaginalis and XMRV, and to more fully characterize the potential role of these infections in the pathogenesis and progression of prostate cancer in large population-based cohorts of men with prostate cancer who have been followed prospectively for more than two decades. Moreover, we aimed to investigate tumor associated inflammation and atrophic lesions as predictors of lethal prostate cancer. 


\section{BODY}

\section{Aim L. To assess the role of the newly identified XMRV virus in prostate carcinogenesis and progression.}

Our initial approach to characterizing XMRV had been to use immunohistochemistry on our constructed tissue microarrays to characterize for presence or absence of the XMRV virus, and an antibody raised against XMRV by a group at Columbia (13). However, protein expression was noted in the prostate tumor epithelium, rather than in the stroma which had been seen in the initial publication (12). As such, we had concerns about the specificity of the protein expression.

The pathologist completed review of cases for circling areas of benign tissue on the tumor blocks for extraction of DNA for the characterization of RNASEL genotype. In preliminary work, we have shown excellent yields of DNA (100-200 ng) from 3 cores of benign tissue, which will be more than sufficient for our genotyping assays. DNA has been extracted from the cases, and the genotyping is being undertaken using a sequenom platform.

We have completed two biomarker studies on the tumor tissue microarrays that are critical to this study: 1-) Tumor apoptosis using a TUNEL assay to assess extent of tumor tissue undergoing apoptosis, and 2-) cellular proliferation assessed by immunohistochemistry with antibody to ki67. The data on these two markers was generated into SAS databases.

Our pathologist has undertaken and completed a comprehensive review of all cases for evidence of atrophy lesions and chronic and acute inflammation. He reviewed all available H\&E slides from the 680 men. We have characterize for presence of simple atrophy (SA), simple atrophy with cyst formation (SACF), post atrophic hyperplasia (PAH) and partial atrophy (PA); data on evidence of high grade PIN and perineural invasion, as well as for evidence of acute and chronic inflammation (none, mild, moderate/severe). The data were entered into an ACCESS database, indicated by a Research ID, have been reviewed for quality control, and are linked together with the clinical database (Gleason grade, T stage, tumor extent, body mass index, date of diagnosis, date and cause of death) as a SAS database.

In statistical analysis of these data, we have found substantial evidence of atrophy, with $73 \%$ of cases showing at least one atrophic lesions, including $20 \%$ with evidence of the proliferative atrophic lesion PAH. Both chronic (26\%) and acute $(14 \%)$ atrophy were also commonly evident in the tissue specimens. Among 680 men, 220 died of prostate cancer. (Supporting Data, Table 1) We found no overall evidence of PAH and prostate cancer-specific mortality (Odds ratio 1.3, 95\% confidence interval 0.8-1.7). However, men who had both evidence of PAH and moderate to severe inflammation were significantly more likely to die of prostate cancer (Odds ratio $2.5,95 \%$ confidence interval 1.3-3.8) suggesting a joint effect of atrophy and inflammation in prostate cancer progression. The data on inflammation and atrophy will play a critical role in our understanding of the infectious pathogenesis of prostate cancer. These data were presented at the United States and Canadian Academy of Pathology Meeting in San Antonio 2011, and a manuscript summarizing the results has been drafted and was just accepted for publication at Cancer Epidemiology Biomarkers and Prevention (see Appendix 4). In addition, these data have been instrumental in expanding the work to a 
US cohort of men with prostate cancer who are participants in the Health Professionals Follow-up Study, as described below.

We have been in constant contact with Dr. Eric Klein at the Cleveland Clinic with respect to obtaining the antibody for XMRV to be used on our tissue samples. When we requested the extension in 2009, we had been told it would be ready. Throughout 2010, our colleagues kept assuring us that it was near ready. It was not until early 2011 that it became clear that we would not be able to carry out that part of the study, so there are no new data on XMRV to report. At this stage, it does not appear that the methodology is appropriate at this stage to validly address the study aims. Instead, the carry-over funds were used to further analyze our previous data within the Swedish Watchful Waiting Cohort and publish several related papers.

\section{Aim II. To characterize the role of the infectious protozoa $T$. vaginalis in prostate carcinogenesis and progression.}

Much of the preliminary work summarized in Aim I is directly relevant to Aim II of the project, including the clinical data review, tissue retrieval, histologic evaluation, TMA construction, and atrophy/inflammation assessment.

\section{Related work}

Serologic evidence of $T$ vaginalis. Related to this project, we have published a study of $T$ vaginalis serostatus measured in prediagnostic blood and prostate cancer risk and progression in the Physicians' Health Study among 673 incident prostate cancer cases and 673 matched controls. The bloods were collected and stored prospectively, and cases were diagnosed from 1982-2000. The men have been followed prospectively through 2009 for cancer-specific and overall mortality. We found a suggestion of $T$. vaginalis seropositivity and overall prostate cancer risk (Odds ratio 1.23; 95\% confidence interval (CI): 0.94-1.61). Moreover, seropositive men had a 2.2-fold increase in risk of extraprostatic prostate cancer $(95 \% \mathrm{Cl}$ : $1.08-4.37)$ and a 2.7 -fold increase in risk $(95 \%$ $\mathrm{Cl}: 1.37-5.28)$ of cancer that would ultimately progress to distant metastases or prostate cancer-specific death. These data provide compelling evidence of a role of this infectious protozoan in the progression of prostate cancer. The data were presented as an Oral Session in the American Association for Cancer Research Frontiers in Cancer Prevention meeting, and a manuscript of these data was published in Journal of the National Cancer Institute in 2009 and appears in this report as Appendix 2. These exciting results provided convincing evidence and we are now collaborating with researchers in the Southern Community Cohort Study, a racially diverse cohort, to confirm our findings on T vaginalis and prostate cancer. Moreover, we are currently undertaking a study within the HPFS cohort to look at whether the effect of T vaginalis is by common variants in the Toll-like receptor 4 (TLR4) genotype as a marker of the extent of intraprostatic inflammation during infection because $T$. vaginalis has been shown to elicit inflammation through this receptor. We have data on 690 incident prostate cancer cases diagnosed from 1993-2000 and 692 controls comprised this nested case-control study within the Health Professionals Follow-up Study. We previously genotyped 15 common TLR4 single nucleotide polymorphisms (SNPS), and determined $T$. vaginalis serostatus by enzyme-linked immunosorbent assay. $T$. vaginalis seropositivity was associated with an increased risk of prostate cancer among 
TLR4 homozygous wildtypes (odds ratios (ORs) $=1.86-2.18$ ) for SNPs rs6478317, rs 10116253, rs 1927914, rs 10759932, rs 1927911, and rs2149356, whereas no association was observed among variant carriers for these SNPS (P-interaction $=0.01$ 0.07). Interactions were more pronounced for high-grade disease and among infrequent and moderate aspirin users. Our observation of effect modification by TLR4 genotype supports the hypothesis that T. vaginalis infection contributes to prostate carcinogenesis by infection-mediated intraprostatic inflammation. A manuscript summarizing the results of this study is circulated with co-authors.

Correlates of Atrophy/inflammation. Using an identical approach to characterizing atrophy and inflammation in the Swedish cases, our pathology team is now reviewing men with prostate cancer who are participants in the Health Professionals Follow-up Study and Physicians' Health Study. In line with the Swedish cases, we found that onethird of cases exhibited moderate-severe chronic inflammation; one-quarter of the cases had evidence of post-atrophic hyperplasia. The prevalence of both PAH and simple atrophy were higher among specimens that also contained substantial chronic inflammation (Supporting Data, Figure 1). Two of the atrophic lesions, simple atrophy (SA) and simple atrophy with cyst formation (SACF) were positively associated with older age at diagnosis, while the PAH lesions were positively associated with tumor proliferation. (Supporting Data, Figure 2). The frequency of PAH lesions was substantially higher among men with a greater adiposity, as determined by waist to hip ratio. These data were presented in a poster presentation as part of the recent $D o D$ ImPact Meeting in 2011 in Orlando.

RNASEL. RNASEL located at chromosome $1 \mathrm{q} 25$ encodes ribonuclease $\mathrm{L}$, part of the interferon-mediated immune response to viral infection. The initial publication on XMRV identified the virus through comparing differential viral probes according to variation in RNASEL. We investigated the association between variation in RNASEL and prostate cancer risk and progression in a study of 1286 cases and 1264 controls nested within the prospective Physicians' Health Study. Eleven SNPs were selected using the webbased Tagger in the HapMap CEPH panel. Unconditional logistic regression models assessed the relationship between each SNP and incident, advanced stage (T3/T4, T0$\mathrm{T} 4 / \mathrm{M} 1$, lethal disease), and high Gleason grade ( $\geq 7)$ prostate cancer. Further analyses were stratified by calendar year of diagnosis. Cox proportional hazards models examined the relationship between genotype and prostate cancer-specific survival. We also explored associations between genotype and serum inflammatory biomarkers interleukin-6 (IL-6), C-reactive protein (CRP), and TNFR2 using linear regression. Individuals homozygous for the variant allele of rs12757998 had an increased risk of prostate cancer (AA vs. GG; OR: 1.63, 95\% Cl: 1.18-2.25), and more specifically, high grade tumors (OR: 1.90, 95\% Cl: 1.25-2.89) (Supporting Data, Table 2). The same genotype was associated with increased CRP $(p=0.02)$ and IL-6 $(p=0.05)$ levels. Missense mutations R462Q and D541E were associated with an increased risk of advanced stage disease only in the pre-PSA era. There were no significant associations with survival. The results of this study support a link between RNASEL and prostate cancer, and suggest the association may be mediated through inflammation. These data were presented at the American Association for Cancer Research meeting in 2009, and a manuscript summarizing the data was published in Carcinogenesis 2010.

mRNA signature of Gleason grade. Gleason grade is a measure of prostate tumor differentiation, and we have previously shown is a strong predictor of prostate cancer survival. We reasoned that distinct sets of genes or pathways affect or are affected by 
the de-differentiation process and sought to identify an mRNA signature that distinguishes high from low Gleason grade. We measured the mRNA expression of 6,100 genes in prostate tumor tissue from patients in the Swedish Watchful Waiting cohort ( $N=358$ ) and Physicians' Health Study (PHS, $N=109)$. Comparing individuals with Gleason $\leq 6$ to those with Gleason $\geq 8$, we built a 157-gene signature using Prediction Analysis of Microarrays in the Swedish data with good discriminatory ability; when this signature was applied to PHS the discriminatory ability remained high. Applying the signature to men with Gleason 7, the probability of being high grade improved a model's ability to predict lethal disease beyond knowing whether the Gleason score was $4+3$ or $3+4(p=0.01)$. Our expression signature may enhance our understanding of the dedifferentiation process of prostate tumors and may have clinical applications for men with Gleason 7, improving their classification of a high or low risk of dying from cancer and guiding therapy decisions. A manuscript summarizing these data was published Journal of Clinical Oncology in June 2011 and appears in this report as Appendix 3. 


\section{KEY RESEARCH ACCOMPLISHMENTS}

- Completed pathologic review of cohort on extent of inflammation, atrophy, high grade PIN, and perineural invasion on all cases

- Completed biomarker studies on tumor tissue microarrays to assess extent of tumor apoptosis and cellular proliferation

- Created a merged clinical and tissue SAS database, including clinical information, atrophy and inflammation data, and biomarker data for statistical analyses. This resource will be used for future projects

- Completed review of tissue specimens for indentifying histologically normal tissue and completed DNA extraction with excellent DNA yields

- Completed statistical analyses linking data on inflammation and atrophy in relation to prostate cancer-specific mortality with paper under review

- Published manuscript on serostatus for $T$ vaginalis and prostate cancer risk and progression based on the Physicians' Health Study in Journal of the National Cancer Institute

- Identified and validated gene signature of Gleason grade, that discriminates lethal outcomes on Gleason 7 tumors, and published study in Journal of Clinical Oncology

- Identified novel SNP in RNASEL that is associated with high grade prostate cancer, as well as circulating levels of the inflammatory markers; published manuscript summarizing the results in Carcinogenesis

- Identified inflammatory atrophic lesions that are associated with increased risk of lethal prostate cancer; paper in press at Cancer Epidemiol Biomarkers Prev

- Presented the results from this study at international cancer, medical and pathology meetings

- Extending findings from this DoD proposal to test additional related hypotheses on infections, inflammation and prostate cancer, including the interaction between $T$ vaginalis and genetic variants in the Toll Like Receptor gene 


\section{REPORTABLE OUTCOMES}

- Post-doctoral fellow working on this project (Jennifer Rider Stark) was promoted to Instructor, and is currently under review for promotion to Assistant Professor.

- New student working on this project (Mara Meyer) defended her thesis and was appointed as Post-doctoral fellow

- Recruited two new doctoral students from the University of Orebro, Sweden to work on project

- Dr. Stark received a $2^{\text {nd }}$ year of funding for her Career Development Award from the Dana Farber/Harvard Cancer Center Prostate Cancer SPORE based on an extension of this project

- Dr. Mucci was named the Outstanding Young Investigator from the Prostate Cancer Foundation based on experience supported by this award

- Development of prostate tumor tissue repository of TURP specimens and clinical-tumor database

- $\quad$ Presented results at national research meetings

- American Association for Cancer Research Advances in Prostate Cancer conference. 2008.

- American Association for Cancer Research Frontiers in Cancer Prevention Conference. 2008.

- Multi-institutional Prostate Cancer SPORE Retreat, Ft Lauderdale 2010

- United States and Canadian Academy of Pathology, San Antonio

- US Army Prostate Cancer Program ImPACT Meeting, Orlando, FL

- $\quad$ Published manuscripts

- Stark JR, Judson G, Alderete JF, Mundodi V, Kucknoor AS, Giovannucci EL, Platz EA, Sutcliffe S, Fall K, Kurth T, Ma J, Stampfer MJ, Mucci LA. Prospective study of Trichomonas vaginalis infection and prostate cancer incidence and mortality: Physicians' Health Study. J Natl Cancer Inst. 2009 Oct 21;101:1406-11

- Meyer MS, Penney KL, Stark JR, Schumacher FR, Sesso HD, Loda M, Fiorentino $M$, Finn $S$, Flavin RJ, Kurth $T$, Price $A L$, Giovannucci $E L$, Fall K, Stampfer MJ, Ma J, Mucci LA. Genetivariation in RNASEL associated with prostate cancer risk and progression. Carcinogenesis. 2010 Sep;31(9):1597-603.

- Penney KL, Sinnott JA, Fall K, Pawitan Y, Hoshida Y, Kraft P, Stark JR, Fiorentino $M$, Perner $S$, Finn $S$, Calza $S$, Flavin $R$, Freedman $M L$, Setlur $S$, Sesso HD, Andersson SO, Martin N, Kantoff PW, Johansson JE, Adami HO, Rubin MA, Loda M, Golub TR, Andrén O, Stampfer MJ, Mucci $\underline{L A}$. $m R N A$ expression signature of Gleason grade predicts lethal prostate cancer. J Clin Oncol. 2011 Jun 10; 29 (17):2391-6. PubMed PMID:21537050; PubMed Central PMCID: PMC3107753.

- Davidsson S, Fiorentino M, Andrén O, Fang F, Mucci LA, Varenhorst E, Fall K, Rider JR. Inflammation, Focal Atrophic 
Lesions, and Prostatic Intraepithelial Neoplasia (PIN) with Respect to Risk of Lethal Prostate Cancer. Cancer Epidemiol Biomarkers Prev 2011; In Press. 


\section{CONCLUSION}

We have demonstrated our ability to undertake this large cohort and collect archival tumor specimens from 680 men in the Swedish Watchful Waiting cohort. We have demonstrated a proven working relationship with the pathology team, as shown by completion of the construction of the tissue microarrays, standardized Gleason grading, evaluation of atrophy and inflammation, and successful completion of biomarkers on the tissue microarrays. Moreover, our statistical analyses on atrophy-inflammation and prostate cancer-specific mortality, combined with the findings of serologic evidence of $T$ vaginalis and prostate cancer mortality, as well as the SNP in RNASEL provide supportive evidence for the study hypothesis.

Although we were not able to carry out the XMRV assessment on the tissue specimens. However, this project does provide strong evidence of a role of infectious agents and inflammation in prostate pathogenesis. Moreover, the tumor tissue repository we have established as a result of funding from the DoD Prostate Cancer Program represents a unique resource in which to test future hypothesis. Given the substantial biologic heterogeneity of prostate cancer, the proposed project would ultimately have exciting implications for prevention and potentially treatment of prostate cancer. 


\section{REFERENCES}

1. Ferlay J, Bray F, Pisani P, Parkin DM. GLOBCAN 2000: Cancer Incidence, Mortality and Prevalence Worldwide. Lyon: IARCPress, 2001.

2. Steinek G, Helgesen F, Adolfsson J, et al. Quality of life after radical prostatectomy or watchful waiting. New England Journal of Medicine 2002;347:790-796.

3. Holmberg L, Bill-Axelson A, Helgesen F, et al. A randomized trial comparing radical prostatectomy with watchful waiting in early prostate cancer. New England Journal of Medicine 2002;347:781-789.

4. Nelson WG, De Marzo AM, DeWeese TL, Isaacs WB. The role of inflammation in the pathogenesis of prostate cancer. The Journal of Urology 2004;172:S6-S12.

5. Kuper H, Adami HO, Trichopoulos D. Infections as a major preventable cause of human cancer. Journal of Internal Medicine 2000;248:171-183.

6. Palapattu GS, Sutcliffe S, De Marzo AM, Isaacs WB, Nelson WG. Prostate carcinogenesis and inflammation: emerging insights. Carcinogenesis 2004;26:11701181.

7. Irani J, Goujon J-M, Ragni E, et al. High-grade inflammation in prostate cancer as a prognostic factor for biochemical recurrence after radical prostatectomy. Urology 1999;54:467-472.

8. Kuper $\mathrm{H}$, Adami H-O, Trichopoulos D. Infections and a major preventable cause of human cancer. Journal of Internal Medicine 2000;248:171-183.

9. Pisani P, Parkin DM, Munoz N, Ferlay J. Cancer and infections: estimates of the attributable fraction in 1990. Cancer Epidemiology Biomarkers and Prevention 1997;6:387-400.

10. Signorello LB, Adami HO. Prostate Cancer. In: Adami HO, Hunter DJ, Trichopoulos D, eds. Textbook of Cancer Epidemiology. New York: Oxford University Press, 2002:385.

11. Sutcliffe S, Giovannucci E, Alderete JF, et al. Plasma antibodies against Trichomonas vaginalis and subsequent risk of prostate cancer. Cancer Epidemiology Biomarkers and Prevention 2006;15: 939-45.

12. Urisman A, Molinaro RJ, Fischer $\mathrm{N}$, et al. Identification of a novel gammaretrovirus in prostate tumors of patients homozygous for R462Q RNASEL variant. PLOS Pathogens 2006;2:e25.

13. Schlaberg R, Choe DJ, Brown KR, Thaker HM, Singh IR.XMRV is present in malignant prostatic epithelium and is associated with prostate cancer, especially highgrade tumors. Proc Natl Acad Sci U S A. 2009; 106(38):16351-6. 


\section{SUPPORTING DATA}

Table 1. Prevalence of atrophy and inflammation in the Swedish Watchful Waiting Cohort, overall and by Gleason grade

\section{Focal Prostate Atrophy}

Proliferative atrophic hyperplasia

Simple atrophy

Simple atrophy with cyst

formation

Partial atrophy

\begin{tabular}{ccccc} 
Overall & $\mathbf{5}$ & \multicolumn{3}{c}{ Gleason grade } \\
$\mathrm{N}=619$ & $\mathrm{~N}=288$ & $\mathrm{~N}=\mathbf{4}$ & $\mathbf{4 + 3}$ & $\mathbf{8 - 1 0}$ \\
\hline $125(20.2 \%)$ & $18.4 \%$ & $25.6 \%$ & $21.1 \%$ & $18.3 \%$ \\
& & & & $\mathrm{~N}=90$ \\
$367(59.3 \%)$ & $61.8 \%$ & $59.5 \%$ & $56.7 \%$ & $55.0 \%$ \\
$38(6.1 \%)$ & $7.6 \%$ & $1.7 \%$ & $8.9 \%$ & $5.0 \%$ \\
$11(1.8 \%)$ & $2.8 \%$ & $2.5 \%$ & $0 \%$ & $0 \%$
\end{tabular}

\section{Chronic inflammation}

None

Mild

$164(26.5 \%) \quad 24.3 \%$

$51.0 \%$

Moderate/Severe

$\begin{array}{ll}296(47.8 \%) & 51.0 \% \\ 159(25.7 \%) & 24.7 \%\end{array}$

$22.3 \%$

$52.1 \%$

$15.6 \%$

$28.9 \%$

$40.0 \%$

$34.2 \%$

$159(25.7 \%)$

$31.1 \%$

$41.7 \%$

$84(13.6 \%) \quad 16.7 \%$

$14.1 \%$

$12.2 \%$

$6.7 \%$

Perineural invasion

$43(7.0 \%)$

$0.7 \%$

$3.3 \%$

$10.0 \%$

$23.3 \%$

High grade PIN

$81(13.1 \%)$

$6.6 \%$

$16.5 \%$

$21.1 \%$

$19.2 \%$ 
High Grade disease (Gleason $\geq 7$ )

\begin{tabular}{|c|c|c|c|c|c|c|c|c|c|}
\hline \multirow[b]{2}{*}{ SNP* } & \multirow[b]{2}{*}{ Genotype } & \multicolumn{4}{|c|}{ as } & \multicolumn{4}{|c|}{ ortallt } \\
\hline & & cases (n) & OR† & $95 \% \mathrm{Cl}$ & $\mathrm{p} \ddagger$ & cases $(n)$ & OR† & $95 \% \mathrm{Cl}$ & $\mathrm{p} \ddagger$ \\
\hline rs682585 & $\begin{array}{l}\text { GG (ref) } \\
\text { GA } \\
A A\end{array}$ & $\begin{array}{c}173 \\
203 \\
61\end{array}$ & $\begin{array}{l}1.00 \\
1.03 \\
0.78\end{array}$ & $\begin{array}{c}\text { ref } \\
(0.81,1.31) \\
(0.56,1.10)\end{array}$ & 0.24 & $\begin{array}{c}93 \\
106 \\
28\end{array}$ & $\begin{array}{l}1.00 \\
0.97 \\
0.63\end{array}$ & $\begin{array}{c}\text { ref } \\
(0.71,1.33) \\
(0.40,1.01)\end{array}$ & 0.12 \\
\hline $\begin{array}{l}\text { rs486907 } \\
\text { (R462Q) }\end{array}$ & $\begin{array}{l}\text { GG (ref) } \\
\text { GA } \\
\text { AA }\end{array}$ & $\begin{array}{c}190 \\
185 \\
56\end{array}$ & $\begin{array}{l}1.00 \\
0.91 \\
0.95\end{array}$ & $\begin{array}{c}\text { ref } \\
(0.71,1.15) \\
(0.67,1.36)\end{array}$ & 0.72 & $\begin{array}{c}86 \\
100 \\
39\end{array}$ & $\begin{array}{l}1.00 \\
1.05 \\
1.51\end{array}$ & $\begin{array}{l}(0.76,1.45) \\
(0.98,2.34)\end{array}$ & 0.17 \\
\hline $\begin{array}{l}\text { rs627928 } \\
\text { (D541E) }\end{array}$ & $\begin{array}{l}\text { TT (ref) } \\
\text { TG } \\
\text { GG }\end{array}$ & $\begin{array}{l}90 \\
200 \\
132\end{array}$ & $\begin{array}{l}1.00 \\
1.17 \\
1.10\end{array}$ & $\begin{array}{c}\text { ref } \\
(0.88,1.57) \\
(0.80,1.50)\end{array}$ & 0.56 & $\begin{array}{c}39 \\
108 \\
73\end{array}$ & $\begin{array}{l}1.00 \\
1.43 \\
1.42\end{array}$ & $\begin{array}{c}\text { ref } \\
(0.95,2.15) \\
(0.92,2.19)\end{array}$ & 0.18 \\
\hline rs533259 & $\begin{array}{l}\text { CC (ref) } \\
\text { CT/TT }\end{array}$ & $\begin{array}{r}377 \\
57\end{array}$ & $\begin{array}{l}1.00 \\
1.09\end{array}$ & $\begin{array}{c}\text { ref } \\
(0.78,1.51)\end{array}$ & 0.62 & $\begin{array}{c}202 \\
26\end{array}$ & $\begin{array}{l}1.00 \\
1.03\end{array}$ & $\begin{array}{c}\text { ref } \\
(0.65,1.63)\end{array}$ & 0.91 \\
\hline rs11807829 & $\begin{array}{l}A A \text { (ref) } \\
A G \\
G G\end{array}$ & $\begin{array}{c}204 \\
175 \\
43\end{array}$ & $\begin{array}{l}1.00 \\
0.87 \\
0.80\end{array}$ & $\begin{array}{c}\text { ref } \\
(0.68,1.10) \\
(0.55,1.17)\end{array}$ & 0.34 & $\begin{array}{l}103 \\
82 \\
25\end{array}$ & $\begin{array}{l}1.00 \\
0.76 \\
0.98\end{array}$ & $\begin{array}{c}\text { ref } \\
(0.55,1.05) \\
(0.60,1.60)\end{array}$ & 0.23 \\
\hline rs627839 & $\begin{array}{l}\text { CC (ref) } \\
\text { CA } \\
\text { AA }\end{array}$ & $\begin{array}{c}125 \\
214 \\
98\end{array}$ & $\begin{array}{l}1.00 \\
1.12 \\
1.00\end{array}$ & $\begin{array}{c}\text { ref } \\
(0.86,1.45) \\
(0.73,1.36)\end{array}$ & 0.61 & $\begin{array}{c}63 \\
113 \\
50\end{array}$ & $\begin{array}{l}1.00 \\
1.13 \\
1.09\end{array}$ & $\begin{array}{c}\text { ref } \\
(0.80,1.60) \\
(0.72,1.66)\end{array}$ & 0.78 \\
\hline rs10911099 & $\begin{array}{l}\text { AA (ref) } \\
A G / G G\end{array}$ & $\begin{array}{l}330 \\
109\end{array}$ & $\begin{array}{l}1.00 \\
1.16\end{array}$ & $\begin{array}{c}\text { ref } \\
(0.90,1.50)\end{array}$ & 0.26 & $\begin{array}{c}165 \\
60\end{array}$ & $\begin{array}{l}1.00 \\
1.25\end{array}$ & $\begin{array}{c}\text { ref } \\
(0.89,1.77)\end{array}$ & 0.20 \\
\hline rs12729828 & $\begin{array}{l}\text { GG (ref) } \\
\text { GA/AA }\end{array}$ & $\begin{array}{l}317 \\
99\end{array}$ & $\begin{array}{l}1.00 \\
1.12\end{array}$ & $\begin{array}{c}\text { ref } \\
(0.85,1.46)\end{array}$ & 0.43 & $\begin{array}{c}172 \\
46\end{array}$ & $\begin{array}{l}1.00 \\
1.00\end{array}$ & $\begin{array}{c}\text { ref } \\
(0.70,1.45)\end{array}$ & 0.99 \\
\hline rs635261 & $\begin{array}{l}\text { GG (ref) } \\
\text { CG } \\
\text { CC }\end{array}$ & $\begin{array}{c}177 \\
187 \\
65\end{array}$ & $\begin{array}{l}1.00 \\
0.89 \\
0.83\end{array}$ & $\begin{array}{c}\text { ref } \\
(0.70,1.13) \\
(0.59,1.15)\end{array}$ & 0.45 & $\begin{array}{l}90 \\
92 \\
38\end{array}$ & $\begin{array}{l}1.00 \\
0.80 \\
0.89\end{array}$ & $\begin{array}{c}\text { ref } \\
(0.57,1.10) \\
(0.58,1.36)\end{array}$ & 0.39 \\
\hline rs12757998 & $\begin{array}{l}\text { GG (ref) } \\
\text { GA } \\
\text { AA }\end{array}$ & $\begin{array}{c}208 \\
161 \\
43\end{array}$ & $\begin{array}{l}1.00 \\
1.02 \\
1.90\end{array}$ & $\begin{array}{c}\text { ref } \\
(0.80,1.30) \\
(1.25,2.89)\end{array}$ & 0.003 & $\begin{array}{l}109 \\
72 \\
16\end{array}$ & $\begin{array}{l}1.00 \\
0.84 \\
1.44\end{array}$ & $\begin{array}{c}\text { ref } \\
(0.60,1.17) \\
(0.79,2.63)\end{array}$ & 0.22 \\
\hline rs12034888 & $\begin{array}{l}\text { CC (ref) } \\
\text { CT/TT }\end{array}$ & $\begin{array}{c}353 \\
74\end{array}$ & $\begin{array}{l}1.00 \\
1.13\end{array}$ & $\begin{array}{c}\text { ref } \\
(0.84,1.53)\end{array}$ & 0.42 & $\begin{array}{c}182 \\
42\end{array}$ & $\begin{array}{l}1.00 \\
1.26\end{array}$ & $\begin{array}{c}\text { ref } \\
(0.86,1.85)\end{array}$ & 0.25 \\
\hline
\end{tabular}

* SNPs listed by genomic position

$\dagger$ Odds ratios adjusted for age, smoking status, follow-up time, $\ddagger$ p-values from likelihood ratio test

Advanced stage (T3/T4/N1/M1, or PCa mortality) 
Figure 1. Frequency of focal atrophy lesions by chronic inflammation grade in the Physicians' Health Study and Health Professionals Follow-up Study, 1982-2009

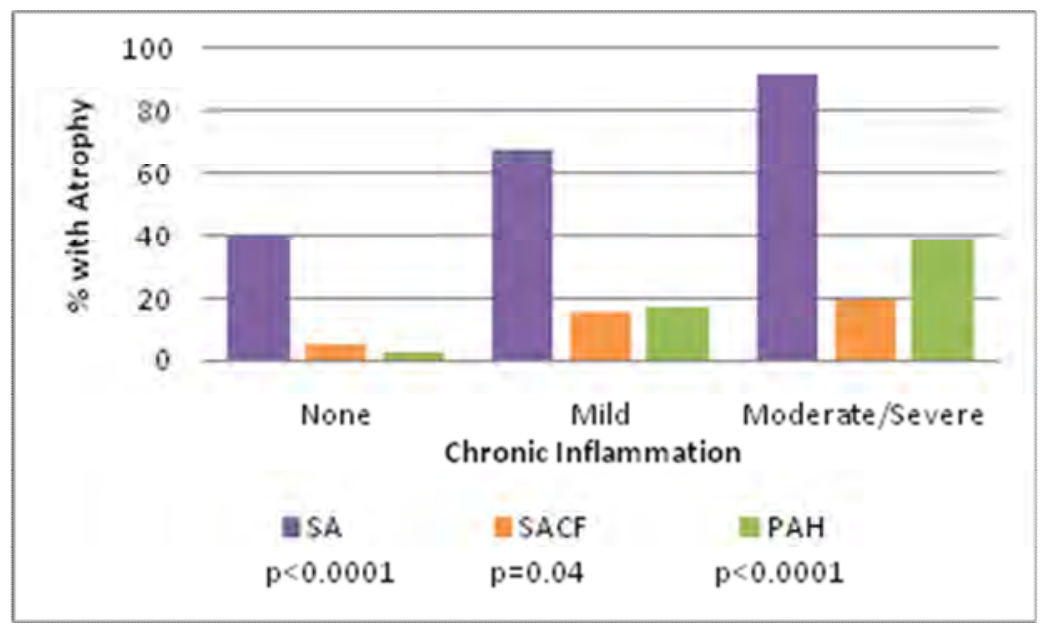

Figure 2. Direction of association between presence of focal atrophy/ chronic inflammation by clinical and tumor characteristics in the Physicians' Health Study and Health Professionals Follow-up Study, 1982-2009

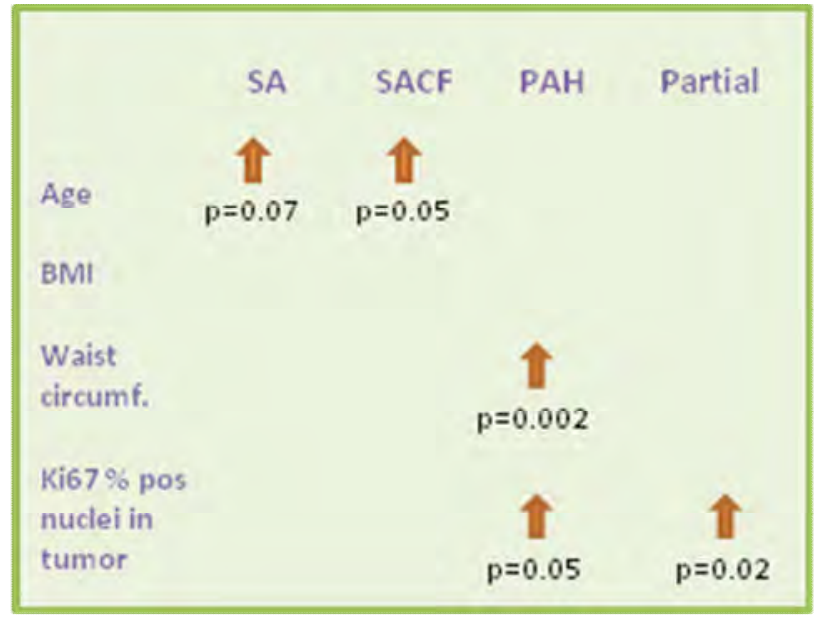




\section{APPENDICES}

1. Personnel receiving pay from the research effort

2. Stark JR, Judson G, Alderete JF, Mundodi V, Kucknoor AS, Giovannucci EL, Platz EA, Sutcliffe S, Fall K, Kurth T, Ma J, Stampfer MJ, Mucci LA. Prospective study of Trichomonas vaginalis infection and prostate cancer incidence and mortality:

Physicians' Health Study. J Natl Cancer Inst. 2009 Oct 21;101:1406-11.

3. Penney KL, Sinnott JA, Fall K, Pawitan Y, Hoshida Y, Kraft P, Stark JR, Fiorentino M, Perner S, Finn S, Calza S, Flavin R, Freedman ML, Setlur S, Sesso HD, Andersson SO, Martin N, Kantoff PW, Johansson JE, Adami HO, Rubin MA, Loda M, Golub TR, Andrén O, Stampfer MJ, Mucci LA. mRNA expression signature of Gleason grade predicts lethal prostate cancer. J Clin Oncol. 2011 Jun 10; 29 (17) :2391-6. PubMed PMID:21537050; PubMed Central PMCID: PMC3107753.

4. Davidsson S, Fiorentino M, Andrén O, Fang F, Mucci LA, Varenhorst E, Fall K, Stark JR. Focal Prostate Atrophic Lesions and risk of Lethal Prostate Cancer. Cancer Epidemiology Biomarkers and Prevention. Accepted.

5. Abstract: Genetic variation in RNASEL and prostate cancer risk. Presented at American Association for Cancer Research Advances in Prostate Cancer conference. 2008.

6. Abstract: Trichomonas vaginalis infection and prostate cancer incidence and mortality: A prospective study in the Physicians' Health Study. Presented at American Association for Cancer Research Frontiers in Cancer Prevention Conference. 2008.

7. Abstract: Post-Atrophic Hyperplasia Lesions and Prostate Cancer Survival. Presented at Multi-institutional Prostate Cancer SPORE Retreat. 2010.

8. Abstract: Focal Prostate Atrophic Lesions and Risk of Lethal Prostate Cancer. Presented at United States and Canadian Academy of Pathology Conference. 2011. 


\section{Personnel receiving pay from the research effort}

1. Lorelei Mucci, ScD Associate Professor Department of Epidemiology Harvard School of Public Health

2. Whitney Hendrickson

Research Assistant

Department of Epidemiology

Harvard School of Public Health

3. David Havelick

Program Coordinator

Department of Epidemiology

Harvard School of Public Health 


\title{
Prospective Study of Trichomonas vaginalis Infection and Prostate Cancer Incidence and Mortality: Physicians' Health Study
}

\author{
Jennifer R. Stark, Gregory Judson, John F. Alderete, Vasanthakrishna Mundodi, Ashwini S. Kucknoor, \\ Edward L. Giovannucci, Elizabeth A. Platz, Siobhan Sutcliffe, Katja Fall, Tobias Kurth, Jing Ma, Meir \\ J. Stampfer, Lorelei A. Mucci
}

Background A recent nested case-control study found that the presence of antibodies against Trichomonas vaginalis, a common nonviral sexually transmitted infection, was positively associated with subsequent incidence of prostate cancer. We confirmed these findings in an independent population and related serostatus for antibodies against $T$ vaginalis to prostate cancer incidence and mortality.

Methods We conducted a case-control study nested within the Physicians' Health Study that included 673 case subjects with prostate cancer and 673 individually matched control subjects who had available plasma samples. Plasma from blood samples collected at baseline was assayed for antibodies against $T$ vaginalis with an enzyme-linked immunosorbent assay. We used conditional logistic regression to estimate the odds ratios (ORs) of incident prostate cancer, extraprostatic prostate cancer, and cancer that would ultimately progress to bony metastases or prostate cancer-specific death.

Results Although not statistically significant, the magnitude of the association between $T$ vaginalis-seropositive status and overall prostate cancer risk $(O R=1.23,95 \%$ confidence interval $[\mathrm{Cl}]=0.94$ to 1.61 ) was similar to that reported previously. Furthermore, a seropositive status was associated with statistically significantly increased risks of extraprostatic prostate cancer ( $O R=2.17,95 \% \mathrm{Cl}=1.08$ to 4.37 ) and of cancer that would ultimately progress to bony metastases or prostate cancer-specific death ( $\mathrm{OR}=2.69,95 \% \mathrm{Cl}=1.37$ to 5.28 ).

Conclusions This large prospective case-control study obtained further support for an association between a seropositive status for antibodies against $T$ vaginalis and the risk of prostate cancer, with statistically significant associations identified for the risk of extraprostatic prostate cancer and for clinically relevant, potentially lethal prostate cancer.

J Natl Cancer Inst 2009;101:1-6

A number of inflammation-related factors have been implicated in prostate cancer risk and progression, but the origin of inflammation is unclear (1). Infections are one possible source. Trichomonas vaginalis is a common nonviral sexually transmitted infection, with an estimated 174 million annual infections globally (2). Prevalence in American men ranges from approximately $3 \%$ among young men in the general population (3) to $65 \%$ among military personnel with nongonococcal urethritis (4). Little is known about the prevalence of infection in older men; however, in contrast to other common sexually transmitted infections, the infection has been observed to be more prevalent among men aged 25-39 years than in men aged 18-20 years $(3,5)$. Urethral symptoms associated with $T$ vaginalis tend to be less severe than other common sexually transmitted infections, such as those due to Chlamydia trachomatis or Neisseria gonorrboeae (6). Furthermore, more recent studies have found that $T$ vaginalis is associated with asymptomatic infections in 50\%-75\% of infected men $(5,7)$. Consequently, many men are unaware that they are infected with the parasite.
Men infected with $T$ vaginalis often experience spontaneous resolution, as shown by decreasing rates of infection with time

Affiliations of authors: Department of Epidemiology (JRS, GJ, ELG, KF, TK, MJS, LAM) and Department of Nutrition (ELG, MJS), Harvard School of Public Health, Boston, MA; Channing Laboratory (JRS, ELG, JM, MJS, LAM) and Division of Preventive Medicine (TK), Department of Medicine, Brigham and Women's Hospital and Harvard Medical School, Boston, MA; School of Molecular Biosciences, Washington State University, Pullman, WA (JFA, VM, ASK); Department of Epidemiology, Johns Hopkins Bloomberg School of Public Health, Baltimore, MD (EAP); Alvin J. Siteman Cancer Center and Department of Surgery, Washington University School of Medicine, St. Louis, MO (SS); Department of Medical Epidemiology and Biostatistics, Karolinska Institutet, Stockholm, Sweden (KF); Institut National de la Santé et de la Recherche Médicale, Unit 708 Neuroepidemiology and Pierre et Marie Curie University, Paris, France (TK).

Correspondence to: Jennifer R. Stark, ScD, Department of Epidemiology, Harvard School of Public Health, 677 Huntington Ave, Boston, MA 02115 (e-mail: stark@hsph.harvard.edu).

See "Funding" and "Notes" following "References."

DOI: 10.1093/jnci/djp306

(C) The Author 2009. Published by Oxford University Press. All rights reserved. For Permissions, please e-mail: journals.permissions@oxfordjournals.org. 


\section{CONTEXT AND CAVEATS}

\section{Prior knowledge}

The presence of antibodies against Trichomonas vaginalis, a common nonviral sexually transmitted infection, has been positively associated with subsequent incidence of prostate cancer.

\section{Study design}

Nested case-control study that included case subjects with prostate cancer and individually matched control subjects who had available plasma samples that were collected at baseline. Plasma was assayed for antibodies against $T$ vaginalis. The relationship of incident prostate cancer, extraprostatic prostate cancer, and cancer known to progress to bony metastases or prostate cancer-specific death was investigated.

\section{Contribution}

The size of the association between $T$ vaginalis-seropositive status and overall prostate cancer risk, although not statistically significant, was similar to that reported previously. A seropositive status was associated with statistically significantly increased risks of extraprostatic prostate cancer, cancer that is known to progress to bony metastases, or prostate cancer-specific death.

\section{Implications}

Further investigation is warranted to determine whether local prostatic inflammation could lead to downstream events that influence prostate cancer risk and to confirm the association between $T$ vaginalis serostatus and aggressive prostate cancer.

\section{Limitations}

The time between $T$ vaginalis infection and blood collection was not known. Men with $T$ vaginalis infection might visit their physicians more frequently than those without such infection and so increase the possibility of prostate cancer diagnosis. Because other sexually transmitted infections occur concurrently with $T$ vaginalis infections, the possibility that $T$ vaginalis is acting as a marker for another pathogen cannot be ruled out.

\section{From the Editors}

since last sexual contact with an infected partner (8) and natural history studies (9), in which as many as one-third of men cleared the infection within 2 weeks without treatment (7). Nevertheless, a smaller proportion of men experience long-term asymptomatic infection $(7,9)$. T vaginalis can ascend the urethra to the prostate and infect the prostate epithelium $(10,11)$, and in that epithelium, it is associated with evidence of acute and chronic inflammation (10). As such, chronic prostatic infection with $T$ vaginalis may initiate an inflammatory response that could increase the risk of developing prostate cancer (10) and increase the risk of disease progression.

A recent case-control study (12) nested in the Health Professionals Follow-up Study found that seroprevalence of $T$ vaginalis infection was positively associated with subsequent prostate cancer risk, with a suggestion of the greatest risk for more aggressive disease that was defined as high Gleason grade disease. As a follow-up on the positive finding between $T$ vaginalis serostatus and prostate cancer risk, we conducted a large nested casecontrol study within the Physicians' Health Study to further investigate a potential association between $T$ vaginalis serostatus and prostate cancer incidence. We also investigated potential associations between $T$ vaginalis serostatus and subgroups of prostate cancer defined by tumor stage, tumor grade, age at diagnosis, and cancer that ultimately progressed to bony metastases or prostate cancer-specific death.

\section{Study Subjects and Methods}

\section{Study Population}

The Physicians' Health Study $(13,14)$ was initiated in 1982 as a randomized, double-blind, placebo-controlled trial of aspirin and $\beta$-carotene for the primary prevention of cardiovascular disease and cancer. The study included 22071 healthy US male physicians aged $40-84$ years at baseline. Before being randomly assigned to a treatment group, 14916 (68\%) of the 22071 men provided a blood sample (15). These participants constitute the study base for the nested case-control study.

We included 673 case subjects who were diagnosed with prostate cancer up to 18 years after blood collection (1982-2000) and who had available plasma samples. We selected 673 control subjects from the population at risk at the time of the case subject's diagnosis (ie, those who had provided blood, had not had a prostatectomy, and had not reported a diagnosis of prostate cancer at the time the case subject was diagnosed with prostate cancer). For statistical efficiency, control subjects were individually matched to case subjects by age (within 1 year), smoking status (never, former, or current), and follow-up time.

\section{Laboratory Assessment}

Plasma from prospectively collected blood samples from each case subject and his matched control subject (stored at $-80^{\circ} \mathrm{C}$ ) was thawed and assayed for antibodies against $T$ vaginalis with an assay that detects IgG antibodies against purified, recombinant $\alpha$-actinin protein from $T$ vaginalis. Enzyme-linked immunosorbent assays were optimized with known negative and positive pooled plasma of uninfected individuals and patients with trichomonosis, respectively, that gave reproducible readings after incubation with microtiter wells containing immobilized $\alpha$-actinin. In this study, paired plasma samples from case and control subjects were diluted at 1:10 (vol/vol) in phosphate-buffered saline-Tween-20 containing 5\% skim milk, and $100 \mu \mathrm{L}$ of the diluted plasma was added to each well of a 96-well plate (Nunc, Rochester, NY). After incubation for 3 hours at $37^{\circ} \mathrm{C}$, the plates were washed three times with phosphate-buffered salineTween-20 followed by the addition of $100 \mu \mathrm{L}$ of secondary goat anti-human IgG (Fc-specific) conjugated to horseradish peroxidase at a 1:1500 dilution in phosphate-buffered saline-Tween-20 containing $5 \%$ skim milk to each well. Plates were incubated again for 1 hour at $37^{\circ} \mathrm{C}$ and then washed three times with phosphatebuffered saline-Tween-20. Color was allowed to develop by adding $100 \mu \mathrm{L}$ of substrate solution per well (2,2'-azino-bis(3-ethylbenzthiazoline-6-sulphonic acid); phosphate-citrate buffer with $0.03 \%$ sodium perborate, Sigma Chemical Co, St. Louis, MO) according to the manufacturer's recommendations, and plates were incubated at room temperature for 10 minutes. Absorbance values at a wavelength of $405 \mathrm{~nm}$ were then obtained by examining the supernatants spectrophotometrically with an enzyme-linked immunosorbent assay plate reader (Bio-Tek instruments, Inc, Winooski, VT). 
Case-control sample pairs were assayed in adjoining wells, with blinding of laboratory personnel as to the case-control status of the samples. All samples were tested in duplicate and inferences were based on the mean of duplicate values. To create absorbance scores, we used a control plasma panel consisting of pooled plasma from known seronegative patients and four plasma samples with increasing seropositivity. We divided the mean duplicate absorbance value for each seropositive sample in the control panel by the mean duplicate absorbance value of the seronegative control plasma to obtain a minimum positive to negative $(\mathrm{P} / \mathrm{N})$ ratio for each absorbance score $(0=1$ to $<1.81 ; 1=1.81$ to $<2.78 ; 2=2.78$ to $<3.31 ; 3=3.31$ to $<4.07$; or $4=\geq 4.07$ ). The positive to negative ratio was computed for all case subjects with prostate cancer and all control subjects, and the resulting values were then compared with the specified cut points determined from the control panel to assign an absorbance score (ie, 0, 1, 2, 3, or 4). Samples from the control panel were included with each plate to monitor reproducibility; values for these samples always fell within the previously determined range. Samples with absorbance scores of 3 or 4 were considered positive for history of trichomonosis. We also included 29 quality-control duplicate or triplicate samples that were randomly distributed across plates. Concordance in serostatus was achieved for 26 of 29 (90\%) of the quality-control samples; 17 of 26 of the concordant replicate samples were seropositive.

\section{Statistical Analysis}

We used conditional logistic regression to analyze prostate cancer risk according to serostatus adjusting for matching factors. Odds ratios (ORs) and 95\% confidence intervals (CIs) were estimated by comparing men who were $T$ vaginalis seropositive at baseline with men who were $T$ vaginalis seronegative. We additionally controlled for randomization to aspirin assignment and body mass index (continuous) and evaluated risk within subgroups of stage and grade at diagnosis. All $P$ values were from two-sided statistical tests, with $\alpha$ of .05 considered to be statistically significant.

Analyses were undertaken with the SAS Statistical Analysis version 9.1.3 (SAS Institute, Cary, NC). The research protocol was approved by the institutional review board at Partners Healthcare. Questionnaire data were collected with implied consent, and biomarker data were collected with written authorization.

\section{Results}

On average, case subjects were aged 68.7 years ( $\mathrm{SD}= \pm 7.4$ years) at diagnosis. Most case subjects were diagnosed with welldifferentiated tumors (54\% with a Gleason score of 2-6) at a localized stage ( $83 \%$ with a stage of T1 or T2). Mean time between blood collection and prostate cancer diagnosis was 9.3 years (range = 0.3-17.9 years). The seroprevalence of $T$ vaginalis infection was $21 \%$ in control subjects and $25 \%$ in case subjects (Table 1). T vaginalis absorbance scores were not associated with age or baseline prostate-specific antigen (PSA) levels in case subjects or control subjects.

$T$ vaginalis seropositivity was not statistically significantly associated with total prostate cancer risk $(\mathrm{OR}=1.23,95 \% \mathrm{CI}=0.94$ to 1.61$)$ or high-grade disease (OR for Gleason 7-10 scores $=1.10$, 95\% $\mathrm{CI}=0.72$ to 1.68$)$. However, serological evidence of $T$ vaginalis infection was associated with a statistically significant increase in the risk of diagnosis of advanced-stage prostate cancer $(\mathrm{OR}=2.17$, $95 \% \mathrm{CI}=1.08$ to 4.37$)$ and in the risk of cancer that would ultimately progress to distant metastases or cancer-specific death $(\mathrm{OR}=$ $2.69,95 \% \mathrm{CI}=1.37$ to 5.28 ) (Table 1 ). We also found that the association between $T$ vaginalis and prostate cancer was stronger for men who were diagnosed more closely to blood collection (Table 1). Compared with case subjects overall $(\mathrm{n}=673)$, the 94 case subjects who were diagnosed within 5 years of blood collection tended to be somewhat older at diagnosis (eg, those who were aged $>65$ years $=72[77 \%]$ vs $452[67 \%])$ and more advanced (eg, those who were at stage T3 or T4, N1, or M1 = 23 [25\%] vs 105 [16\%]). However, cross-classifying men on these characteristics suggested that the time scale that most influenced effect estimates was the duration between blood collection and diagnosis. Given the observed increased risk for cancer soon after blood collection, we explored the association between $T$ vaginalis serostatus and lethal prostate cancer, according to years from blood collection to diagnosis. Among the 39 men diagnosed with lethal cancer within 5 years of blood collection and their matched control subjects, men positive for history of trichomonosis $(n=15)$ were statistically significantly more likely to develop lethal prostate cancer than seronegative men $(\mathrm{OR}=6.4,95 \% \mathrm{CI}=1.5$ to 27.9$)$.

\section{Discussion}

In this large nested case-control study, we provide further evidence to support the previously reported association between a $T$ vaginalis-seropositive status and prostate cancer risk (12). The magnitude of the overall association of $T$ vaginalis-seropositive status with incidence in our study, although not statistically significant, was similar to that observed in the previous case-control study nested in the Health Professionals Follow-up Study (OR = $1.43,95 \% \mathrm{CI}=1.00$ to 2.03). The Health Professionals Follow-up Study found a suggestion that infection was primarily associated with more aggressive disease, as shown by the higher Gleason scores at diagnosis, but small numbers prohibited a subgroup analysis among men with advanced disease. In this analysis with more than two decades of follow-up for case subjects with prostate cancer, we found that $T$ vaginalis-seropositive status was primarily associated with clinically relevant prostate cancer. That is, compared with a seronegative status, a seropositive status before cancer diagnosis was associated with a statistically significant risk of developing prostate cancer that was diagnosed at an advanced stage. Moreover, T vaginalis infection appears to be associated with cancer that will ultimately progress to bony metastases and prostate cancer death, independent of body mass index, smoking status, aspirin randomization group, age at diagnosis, and tumor stage and grade. We found no evidence of a stronger association with higher Gleason grade but the subjectivity of Gleason grading and the shift in scores over time (16-18) could explain this discrepancy, because Gleason scores in the Health Professionals Follow-up Study tended to be assigned more recently and, thus, may be better predictors of lethal disease (18).

Our study had several limitations. Because all men provided blood samples in 1982 and all $T$ vaginalis assays of plasma samples were completed in 2008 , the performance of the assay should not 
Table 1. Association between Trichomonas vaginalis antibody serostatus and prostate cancer risk among 673 matched pairs nested in the Physicians' Health Study (1982-2000)*

\begin{tabular}{|c|c|c|}
\hline & \multicolumn{2}{|c|}{$T$ vaginalis serostatus } \\
\hline & Negative & Positive \\
\hline Control subjects, No. (\%) & $529(78.6)$ & $144(21.4)$ \\
\hline \multicolumn{3}{|l|}{ All prostate cancer } \\
\hline Case subjects, No. (\%) & $508(75.5)$ & $165(24.5)$ \\
\hline OR $(95 \% \mathrm{Cl})$ & 1.00 (Ref) & $1.23(0.94$ to 1.61$)$ \\
\hline \multicolumn{3}{|l|}{ Tumor grade: Gleason 2-6 } \\
\hline Case subjects, No. (\%) & $238(76.3)$ & $74(23.7)$ \\
\hline OR $(95 \% \mathrm{Cl})$ & 1.00 (Ref) & $1.16(0.77$ to 1.74$)$ \\
\hline \multicolumn{3}{|l|}{ Tumor grade: Gleason 7-10 } \\
\hline Case subjects, No. (\%) & $204(76.7)$ & $62(23.3)$ \\
\hline OR $(95 \% \mathrm{Cl})$ & 1.00 (Ref) & $1.10(0.72$ to 1.68$)$ \\
\hline \multicolumn{3}{|c|}{ Tumor stage: localized (T1 or T2) } \\
\hline Case subjects, No. (\%) & $406(76.6)$ & $124(23.4)$ \\
\hline OR $(95 \% \mathrm{Cl})$ & 1.00 (Ref) & $1.10(0.81$ to 1.49$)$ \\
\hline \multicolumn{3}{|c|}{ Tumor stage: extraprostatic ( $\mathrm{T} 3$ or $\mathrm{T} 4, \mathrm{~N} 1$, and $\mathrm{M} 1$ ) } \\
\hline Case subjects, No. (\%) & $70(66.7)$ & 35 (33.3) \\
\hline OR $(95 \% \mathrm{Cl})$ & 1.00 (Ref) & $2.17(1.08$ to 4.37$)$ \\
\hline \multicolumn{3}{|l|}{ Nonlethal cancer } \\
\hline Case subjects, No. (\%) & $416(76.7)$ & $126(23.3)$ \\
\hline OR $(95 \% \mathrm{Cl})$ & 1.00 (Ref) & $1.01(0.75$ to 1.37$)$ \\
\hline \multicolumn{3}{|c|}{ Lethal cancer or development of bony metastases } \\
\hline Case subjects, No. (\%) & $92(70.2)$ & $39(29.8)$ \\
\hline OR $(95 \% \mathrm{Cl})$ & 1.00 (Ref) & 2.69 (1.37 to 5.28$)$ \\
\hline \multicolumn{3}{|l|}{ Age at diagnosis: $<65$ y } \\
\hline Case subjects, No. (\%) & 169 (76.5) & $52(23.5)$ \\
\hline OR $(95 \% \mathrm{Cl})$ & 1.00 (Ref) & $1.41(0.86$ to 2.31$)$ \\
\hline \multicolumn{3}{|l|}{ Age at diagnosis: $\geq 65$ y } \\
\hline Case subjects, No. (\%) & $339(75.0)$ & $113(25.0)$ \\
\hline OR $(95 \% \mathrm{Cl})$ & 1.00 (Ref) & $1.12(0.81$ to 1.56$)$ \\
\hline \multicolumn{3}{|c|}{ Time from blood draw to diagnosis: $\leq 5 \mathrm{y}$} \\
\hline Case subjects, No. (\%) & $64(68.1)$ & $30(31.9)$ \\
\hline OR $(95 \% \mathrm{Cl})$ & 1.00 (Ref) & $2.86(1.27$ to 6.47$)$ \\
\hline \multicolumn{3}{|c|}{ Time from blood draw to diagnosis: $>5$ y } \\
\hline Case subjects, No. (\%) & $444(76.7)$ & $135(23.3)$ \\
\hline OR $(95 \% \mathrm{Cl})$ & 1.00 (Ref) & $1.09(0.81$ to 1.46$)$ \\
\hline
\end{tabular}

* From logistic regression conditioned on age and smoking and additionally adjusted for randomized aspirin assignment and body mass index. $\mathrm{Cl}=\mathrm{confidence}$ interval; OR = odds ratio; Ref = referent

be differentially influenced by specimen quality according to date of cancer diagnosis. The unknown period of time between infection and blood collection, however, could influence assay sensitivity. Presumably, men who were infected with $T$ vaginalis closer to the time of blood collection in 1982 would be more likely to have detectable levels of antibodies. Because case and control subjects were matched on age (range $=40-84$ years at blood collection) and timing of infection is more likely to be related to age than calendar time, this misclassification would likely be nondifferential with respect to case-control status and thus lead us to underestimate the true effect estimate.

Two additional biases also warrant attention. First, we found that the association between $T$ vaginalis infection and incidence of prostate cancer was stronger among men diagnosed within 5 years of blood collection. Biomarkers most strongly associated with disease occurring early in a study typically raise concerns about reverse causation (ie, because of the influence of early preclinical disease on the measured biomarker). However, in this study and in all studies of prostate cancer, biological heterogeneity and the impact of PSA testing on the type of prostate cancers diagnosed are important considerations. Consequently, the men who were diagnosed with prostate cancer earlier in our follow-up, before the introduction of PSA testing in 1986, are more likely to be clinically relevant. Thus, the association observed among case subjects who were diagnosed early in follow-up is consistent with the strong association between infection and advanced-stage or lethal disease. For reverse causation to account for our study findings, the carcinogenic process would have to lead to higher levels of detectable antibodies. Although no data have been obtained to support or contest the assumption that levels of antibodies against $T$ vaginalis increase during cancer development, tumorigenesis is known to alter adaptive immune response (19). Second, our findings could be influenced by detection bias if men with $T$ vaginalis infection were more likely to be diagnosed with prostate cancer. To address this possibility, we investigated the relationship of antibody levels to baseline PSA levels but found no association. However, we cannot rule out other urologic symptoms that could bring about diagnosis. Conservatively, serological history of infection with $T$ vaginalis may be a marker of clinically relevant disease, as suggested by the association between infection and development of 
bony metastases or prostate cancer death. More research is required to establish this association.

Disease heterogeneity could also largely explain the apparent discrepancy between our findings and those of a recent study using data from 616 case subjects and 616 matched control subjects sampled from the Prostate Cancer Prevention Trial, a randomized trial of finasteride in 18882 men, which found no association between $T$ vaginalis seropositivity and the incidence of prostate cancer (20). We found that a $T$ vaginalis-seropositive status was principally associated with aggressive, potentially lethal disease. In contrast, most prostate cancers that were analyzed in the Prostate Cancer Prevention Trial were diagnosed at an early stage as a result of annual PSA screening and end-of-study prostate biopsy (21). Evidence is accumulating that the risk factors for lethal and indolent prostate cancer may differ. In an analysis in the Health Professionals Follow-up Study that examined 10 risk factors for total or advanced prostate cancer supported by existing literature (22), only four factors were found to have a statistically significant association with overall incidence: African American race, positive family history, higher tomato sauce intake (inversely), and $\alpha$-linolenic acid intake. By contrast, recent smoking history, taller height, higher body mass index, positive family history, and high intakes of total energy, calcium, and linolenic acid were all statistically significantly associated with fatal prostate cancer. Consistent with our study, these results suggest that there may be multiple biological pathways that contribute to particular subgroups of prostate cancer.

The proportions of case subjects and control subjects with high seropositivity for antibodies against $T$ vaginalis were somewhat higher in this study $(24.5 \%$ of case subjects and $21.4 \%$ of control subjects) than in the Prostate Cancer Prevention Trial (15.2\% of case subjects and $15.0 \%$ of control subjects) or the Health Professionals Follow-up Study (13\% of case subjects and 9\% of control subjects) (12). Assays for all three studies were prepared under the direction of the same microbiologist (J. F. Alderete) and used an enzyme-linked immunosorbent assay to detect antibodies against $\alpha$-actinin protein from $T$ vaginalis. In both the Prostate Cancer Prevention Trial and the Physicians' Health Study studies, known seropositive and seronegative control samples were used to determine absorbance score cut points, which were then applied to study case subjects and control subjects. In the Health Professionals Follow-up Study, absorbance score cut points were based on previous serological findings $(23,24)$, because serum samples from positive and negative control subjects were not available. Furthermore, absolute readings of the enzyme-linked immunosorbent assays in all three studies could be influenced by the specific technician conducting the assay and the fact that the laboratory was relocated in December 2007. Thus, differences in assay sensitivity may account for some of the variation in distribution of $T$ vaginalis seropositivity across these three studies, especially given that demographic characteristics do not appear to explain the observed variability. All three studies included men from across the United States. Although African American race and lower socioeconomic status are generally associated with higher rates of sexually transmitted infections (25), including $T$ vaginalis infections (3), the study with the highest proportion of men with a seropositive status (ie, the Physicians' Health Study) has the smallest proportion of African Americans (<1\%) and a relatively high socioeconomic status because all participants are physicians. Further, the mean age at blood collection in all three studies was similar (ie, 66 years in Health Professionals Follow-up Study, 64 years in Prostate Cancer Prevention Trial, and 59 years in Physicians' Health Study).

Because other sexually transmitted infections occur concurrently with $T$ vaginalis infections, we cannot rule out the possibility that $T$ vaginalis is acting as a marker for another infection. However, two studies $(5,6)$ report that concomitant sexually transmitted infections, including those by $N$ gonorrboeae and $C$ trachomatis, occur only in $10 \%-20 \%$ of case subjects, making it unlikely that these particular sexually transmitted infections could account for the observed association. Furthermore, the previous study in the Health Professionals Follow-up Study investigated other common sexually transmitted infections, including those by $N$ gonorrhoeae, Ctrachomatis, Treponemapallidum, and human papillomavirus, and found no association with prostate cancer, except for an inverse association for human herpesvirus type 8 infection $(26,27)$. Nested case-control studies using data from the Nordic biobank consortium found no association between prostate cancer risk and human papillomavirus types 16,18 , and/or 33 (28), herpes simplex virus-2, or human herpesvirus type 8 (29); however, these studies observed a statistically significant inverse association with serological evidence of $C$ trachomatis infection (30). A study nested within the Prostate, Lung, Colorectal, and Ovarian Cancer Screening Trial (20) found that seroprevalence of $C$ trachomatis, human papillomavirus-16 and -18 , herpes simplex virus-2, cytomegalovirus, and human herpesvirus type 8 were not individually associated with prostate cancer risk among white men. Men with one or more sexually transmitted infections, however, had a modest increase in risk of developing prostate cancer $(\mathrm{OR}=1.3,95 \% \mathrm{CI}=1.0$ to 1.6), indicating that the measured infections could perhaps be serving as proxies for another infection such as $T$ vaginalis.

Although our study may elucidate one mechanism by which local prostatic inflammation could arise and lead to downstream events that influence prostate cancer development and progression, studies that focus on local response to infection in the prostate are needed to determine whether $T$ vaginalis is a causal agent. Nonetheless, in light of the limited understanding of factors that lead to lethal prostate cancer, our finding of an association between $T$ vaginalis serostatus and aggressive prostate cancer is noteworthy. If our findings are confirmed, $T$ vaginalis could serve as a marker for adverse outcomes in patients for prostate cancer or, more optimistically, as a target for secondary chemoprevention.

\section{References}

1. De Marzo AM, Platz EA, Sutcliffe S, et al. Inflammation in prostate carcinogenesis. Nat Rev Cancer. 2007;7(4):256-269.

2. World Health Organization. Global Prevalence and Incidence of Selected Curable Transmitted Infections. Geneva, Switzerland: World Health Organization; 2001.

3. Miller WC, Swygard H, Hobbs MM, et al. The prevalence of trichomoniasis in young adults in the United States. Sex Transm Dis. 2005; 32(10):593-598

4. Kuberski T. Evaluation of the indirect hemagglutination technique for study of Trichomonas vaginalis infections, particularly in men. Sex Transm Dis. 1978;5(3):97-102. 
5. Seña AC, Miller WC, Hobbs MM, et al. Trichomonas vaginalis infection in male sexual partners: implications for diagnosis, treatment, and prevention. Clin Infect Dis. 2007;44(1):13-22.

6. Krieger JN, Jenny C, Verdon $M$, et al. Clinical manifestations of trichomoniasis in men. Ann Intern Med. 1993;118(11):844-849.

7. Krieger JN, Verdon M, Siegel N, Holmes KK. Natural history of urogenital trichomoniasis in men. $\mathcal{Z}$ Urol. 1993;149(6):1455-1458.

8. Weston TET, Nichol CS. Natural history of trichomonal infection in males. Br 7 Vener Dis. 1963;39(4):251-257.

9. Krieger JN. Trichomoniasis in men: old issues and new data. Sex Transm Dis. 1995;22(2):83-96.

10. Gardner WA, Culberson DE, Bennett BD. Trichomonas vaginalis in the prostate gland. Arch Pathol Lab Med. 1986;110(5):430-432.

11. van Laarhoven PH. Trichomonas vaginalis, a pathogen of prostatitis. Arch Chir Neerl. 1967;19(3):263-273.

12. Sutcliffe S, Giovannucci E, Alderete JF, et al. Plasma antibodies against Trichomonas vaginalis and subsequent risk of prostate cancer. Cancer Epidemiol Biomarkers Prev. 2006;15(5):939-945.

13. Hennekens CH, Buring JE, Manson JE, et al. Lack of effect of long-term supplementation with beta carotene on the incidence of malignant neoplasms and cardiovascular disease. N Engl 7 Med. 1996;334(18):1145-1149.

14. Final report on the aspirin component of the ongoing Physicians' Health Study Steering Committee of the Physicians' Health Study Research Group. N Engl 7 Med. 1989;321(3):129-135.

15. Gann PH, Hennekens CH, Ma J, Longcope C, Stampfer MJ. Prospective study of sex hormone levels and risk of prostate cancer. 7 Natl Cancer Inst. 1996;88(16):1118-1126.

16. Albertsen PC, Hanley JA, Barrows GH, et al. Prostate cancer and the Will Rogers phenomenon. 7 Natl Cancer Inst. 2005;97(17):1248-1253.

17. Smith EB, Frierson HF Jr, Mills SE, Boyd JC, Theodorescu D. Gleason scores of prostate biopsy and radical prostatectomy specimens over the past 10 years: is there evidence for systematic upgrading? Cancer. 2002; 94(8):2282-2287.

18. Stark JR, Perner S, Stampfer MJ, et al. Gleason score and lethal prostate cancer: does 3 + 4 = 4 + 3? J Clin Oncol. 2009;27(21):3459-3464.

19. de Visser KE, Eichten A, Coussens LM. Paradoxical roles of the immune system during cancer development. Nat Rev Cancer. 2006;6(1):24-37.

20. Sutcliffe S, Alderete JF, Till C, et al. Trichomonosis and subsequent risk of prostate cancer in the Prostate Cancer Prevention Trial. Int 7 Cancer. 2009;124(9):2082-2087.

21. Thompson IM, Ankerst DP, Chi C, et al. Assessing prostate cancer risk: results from the Prostate Cancer Prevention Trial. 7 Natl Cancer Inst. 2006;98(8):529-534.

22. Giovannucci E, Liu Y, Platz EA, Stampfer MJ, Willett WC. Risk factors for prostate cancer incidence and progression in the health professionals follow-up study. Int $\mathcal{F}$ Cancer. 2007;121(7):1571-1578.
23. Addis MF, Rappelli P, Delogu G, Carta F, Cappuccinelli P, Fiori PL. Cloning and molecular characterization of a cDNA clone coding for Trichomonas vaginalis alpha-actinin and intracellular localization of the protein. Infect Immun. 1998;66(10):4924-4931.

24. Addis MF, Rappelli P, Pinto De Andrade AM, et al. Identification of Trichomonas vaginalis alpha-actinin as the most common immunogen recognized by sera of women exposed to the parasite. 7 Infect Dis. 1999; 180(5):1727-1730.

25. Centers for Disease Control and Prevention. Sexually Transmitted Disease Surveillance, 2006. Atlanta, GA: U.S. Department of Health and Human Services; 2007.

26. Sutcliffe S, Giovannucci E, Gaydos CA, et al. Plasma antibodies against Chlamydia trachomatis, human papillomavirus, and human herpesvirus type 8 in relation to prostate cancer: a prospective study. Cancer Epidemiol Biomarkers Prev. 2007;16(8):1573-1580.

27. Sutcliffe S, Giovannucci E, De Marzo AM, Leitzmann MF, Willett WC, Platz EA. Gonorrhea, syphilis, clinical prostatitis, and the risk of prostate cancer. Cancer Epidemiol Biomarkers Prev. 2006;15(11):2160-2166.

28. Korodi Z, Dillner J, Jellum E, et al. Human papillomavirus 16, 18, and 33 infections and risk of prostate cancer: a Nordic nested case-control study. Cancer Epidemiol Biomarkers Prev. 2005;14(12):2952-2955.

29. Korodi Z, Wang X, Tedeschi R, Knekt P, Dillner J. No serological evidence of association between prostate cancer and infection with herpes simplex virus type 2 or human herpesvirus type 8: a nested case-control study. $\mathcal{Z}$ Infect Dis. 2005;191(12):2008-2011.

30. Anttila T, Tenkanen L, Lumme S, et al. Chlamydial antibodies and risk of prostate cancer. Cancer Epidemiol Biomarkers Prev. 2005;14(2):385-389.

\section{Funding}

National Cancer Institute (5R01CA058684-13, 5R01CA042182-20, CA34944, CA40360, CA097193, T32CA009001-32 to J.R.S.), National Heart Lung and Blood Institute (HL-26490, HL-34595), Harvard University Milton Fund (to L.A.M.), Dana-Farber/Harvard Cancer Center Prostate Specialized Program of Research Excellence (to J.R.S.), and Prostate Cancer Foundation (to L.A.M.).

\section{Notes}

The authors had full responsibility for the design of the study, the collection of data, the analysis and interpretation of the data, the decision to submit the manuscript for publication, and the writing of the manuscript.

We are grateful to Ms Jennifer Sinnott and Ms Haiyan Zhang for their assistance with computer programming and data management. We thank the participants of the Physicians' Health Study for their longstanding commitment and participation.

Manuscript received February 17, 2009; revised July 21, 2009; accepted August 4, 2009. 
From Harvard School of Public Health; Harvard Medical School; Harvard Radiation Oncology Program; Channing Laboratory, Brigham and Women's Hospital; DanaFarber Cancer Institute, Boston; The Broad Institute, Cambridge; MA; Uppsala University, Uppsala; Karolinska Institutet, Stockholm; Örebro University Hospital, Örebro, Sweden; Comprehensive Cancer Center, University Hospital of Tuebingen, Tuebingen, Germany; University of Brescia, Brescia, Italy; and Weill Cornell Medical College, New York, NY.

Submitted September 27, 2010; accepted February 22, 2011; published online ahead of print at www.jco.org on May 2, 2011.

Supported by Grants No. 5P50CA09038108 from the Dana-Farber/Harvard Cancer Center Prostate Specialized Programs of Research Excellence program and No. 5R01CA141298 from the National Cancer Institute. The Physicians' Health Study was supported by Grants No. CA-34944, CA-40360, and CA-097193 from the National Cancer Institute and HL-26490 and HL-34595 from the National Heart, Lung, and Blood Institute. The Swedish Watchfu Waiting cohort was supported by the Swedish Cancer Foundation and The Örebro County Council Research Foundation. Supported by National Research Service Award T32 CA009001-32 (K.L.P.), Grant No. GM-074897 (J.A.S.), and the Prostate Cancer Foundation (L.A.M.).

K.L.P. and J.A.S. contributed equally to this work.

Authors' disclosures of potential conflicts of interest and author contributions are found at the end of this article.

Corresponding author: Kathryn L. Penney, MD, Department of Epidemiology, Harvard School of Public Health, 677 Huntington Ave, Boston, MA 02115; e-mail: kpenney@hsph.harvard.edu

C 2011 by American Society of Clinical Oncology

0732-183X/11/2917-2391/\$20.00

DOI: 10.1200/JCO.2010.32.6421

\section{mRNA Expression Signature of Gleason Grade Predicts Lethal Prostate Cancer}

Kathryn L. Penney, Jennifer A. Sinnott, Katja Fall, Yudi Pawitan, Yujin Hoshida, Peter Kraft, Jennifer R. Stark, Michelangelo Fiorentino, Sven Perner, Stephen Finn, Stefano Calza, Richard Flavin, Matthew L. Freedman, Sunita Setlur, Howard D. Sesso, Swen-Olof Andersson, Neil Martin, Philip W. Kantoff, Jan-Erik Johansson, Hans-Olov Adami, Mark A. Rubin, Massimo Loda, Todd R. Golub, Ove Andrén, Meir J. Stampfer, and Lorelei A. Mucci

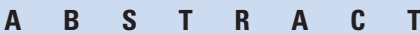

\section{Purpose}

Prostate-specific antigen screening has led to enormous overtreatment of prostate cancer because of the inability to distinguish potentially lethal disease at diagnosis. We reasoned that by identifying an mRNA signature of Gleason grade, the best predictor of prognosis, we could improve prediction of lethal disease among men with moderate Gleason 7 tumors, the most common grade, and the most indeterminate in terms of prognosis.

\section{Patients and Methods}

Using the complementary DNA-mediated annealing, selection, extension, and ligation assay, we measured the mRNA expression of 6,100 genes in prostate tumor tissue in the Swedish Watchful Waiting cohort $(n=358$ ) and Physicians' Health Study (PHS; $n=109$ ). We developed an mRNA signature of Gleason grade comparing individuals with Gleason $\leq 6$ to those with Gleason $\geq 8$ tumors and applied the model among patients with Gleason 7 to discriminate lethal cases.

\section{Results}

We built a 157-gene signature using the Swedish data that predicted Gleason with low misclassification (area under the curve $[A \cup C]=0.91$ ); when this signature was tested in the PHS, the discriminatory ability remained high (AUC $=0.94)$. In men with Gleason 7 tumors, who were excluded from the model building, the signature significantly improved the prediction of lethal disease beyond knowing whether the Gleason score was $4+3$ or $3+4$ $(P=.006)$.

\section{Conclusion}

Our expression signature and the genes identified may improve our understanding of the de-differentiation process of prostate tumors. Additionally, the signature may have clinical applications among men with Gleason 7, by further estimating their risk of lethal prostate cancer and thereby guiding therapy decisions to improve outcomes and reduce overtreatment.

\section{J Clin Oncol 29:2391-2396. (C) 2011 by American Society of Clinical Oncology}

\section{INTRODUCTION}

Widespread use of prostate-specific antigen levels for screening has led to a large increase in the incidence of diagnosed prostate cancer and its treatment. ${ }^{1}$ The overtreatment of prostate cancer is widely recognized; recent randomized trial data suggest that 48 men must be treated to prevent a single prostate cancer-specific death. ${ }^{2}$ A principal difficulty in preventing overtreatment is our current inability to distinguish at diagnosis with sufficient confidence the men who will have an indolent course of disease from those who have aggressive disease. With more than 200,000 cases of prostate cancer diagnosed ${ }^{3}$ and 168,000 prostatectomies $^{4}$ each year in the United States, there is an acute need to improve the ability to distinguish potentially lethal from indolent disease. Several groups, including our own, have used mRNA expression profiling in an attempt to construct a molecular signature of lethal disease. ${ }^{5,6}$ In a variety of analyses, our group developed signatures that predicted lethal disease with a high degree of statistical significance but did not substantially improve on models that included known clinical predictors. ${ }^{5}$

Apart from stage, currently the strongest predictor of lethal prostate cancer is Gleason grade, ${ }^{7}$ a measure of the degree of differentiation of prostate tumor cells; the sum of the primary (predominant) Gleason pattern (1 to 5 ) and the secondary pattern 
(1 to 5 ) is the Gleason score, which ranges from 2 to 10 . In a study using re-reviewed Gleason score from prostatectomy specimens, those with a Gleason score of 8 had a hazard of lethal cancer (dying from prostate cancer or developing distant metastases) that was 7.4 (95\% CI, 2.5 to 22) times higher than those with Gleason $3+4$; patients with a Gleason score of 9 to 10 had an even higher risk of lethal cancer (hazard ratio, $19.1 ; 95 \%$ CI, 7.4 to 49.7 ). ${ }^{8}$ Currently, most men present with apparently low-risk disease, with low tumor volume, and with intermediate Gleason scores of 6 or 7.

Since Gleason grade is such a powerful predictor of lethal disease, we sought an alternative approach to outcome prediction. We reasoned that a molecular signature that discriminates poorly from welldifferentiated tumors defined by Gleason grade might improve prediction of lethal disease and provide insight into the biologic mechanisms underlying the strong relation of Gleason grade and disease progression.

Our work builds on previous studies ${ }^{9-15}$ in which molecular signatures and pathways based on mRNA expression can distinguish tumors according to Gleason grade. However, these past studies were based on small numbers of patients with prostate cancer, the methods and signatures from one study are usually not replicated in another and, importantly, they were not examined with respect to lethal outcomes. In this study, we apply complementary analytic methods to develop and validate an mRNA signature to distinguish high from low Gleason scores in two large, well-characterized cohorts: the Swedish Watchful Waiting Cohort ${ }^{16-18}$ and the Physicians' Health Study (PHS). ${ }^{19,20}$ We then applied the results to determine whether the signature could improve the prediction of lethal outcomes in men with Gleason grade 7.

\section{PATIENTS AND METHODS}

\section{Study Populations}

The expression profiling data in this study were part of a project to identify molecular signatures of lethal and indolent prostate cancer and therefore included men who died from prostate cancer during follow-up (lethal prostate cancer) or who survived at least 10 years after diagnosis (men with indolent prostate cancer). ${ }^{5}$

\section{Swedish Cohort}

The population-based Swedish Watchful Waiting cohort consisted of men diagnosed with incidental prostate cancer discovered through transurethral resection of the prostate (TURP) or adenoma enucleation (ie, stage T1a-b) in the Uppsala-Örebro (1977-1994) and South East (1987-1999) Health Care Regions of Sweden. ${ }^{16-18}$ Eligible patients were identified through population-based prostate cancer databases. In accordance with prevailing standards, patients were followed expectantly. No prostate-specific antigen screening programs were then in place. The archival TURP specimens were identified, and we included in the expression array patients with high-density tumor regions (more than $90 \%$ tumor cells) and high-quality expression data $(\mathrm{n}=358)$.

\section{PHS}

We included samples from men with histologically confirmed prostate cancer who were participants in the PHS, ${ }^{19,20}$ a randomized trial of aspirin and micronutrients in the primary prevention of cardiovascular disease and cancer among healthy US physicians. We have developed an archival repository of tumor specimens from radical prostatectomy (RP) or TURP. For the expression profiling, we selected $116(\mathrm{RP}, \mathrm{n}=102$; TURP, $\mathrm{n}=14)$ patients with high-density tumor area and included only those with high-quality expression data in this analysis $(\mathrm{n}=109)$.

\section{Gleason Grade Re-Review}

We conducted a standardized review of the original hematoxylin and eosin slides from referring hospitals and assigned a primary and secondary Gleason grade. ${ }^{8}$ The review was conducted blinded to the original pathology reports and any clinical data.

\section{RNA Extraction and Profiling}

A pathologist identified regions that were more than $90 \%$ tumor. Cores were taken and deparaffinized; then RNA was extracted as previously described. ${ }^{21}$ Four complementary DNA-mediated annealing, selection, extension, and ligation assay panels were designed for the Illumina platform (Illumina; San Diego, CA) for the discovery of molecular signatures relevant to prostate cancer, as previously described. ${ }^{21}$ The final array consisted of 6,100 genes. The annealing, selection, extension, and ligation assay was found to be well-suited for formalin-fixed tissue $e^{22}$ and provides good correlation with other standard methods, such as quantitative reverse transcriptase polymerase chain reaction (qRT-PCR).

Quality assessment was performed assuming a log-normal distribution of 27control probes present within. We compared each gene measurement with this negative control distribution, considering a gene "present" if its expression level was above the 95 th percentile. For each sample, we computed the proportion of present genes. We excluded poor-quality samples with less than $55 \%$ present measurements. The remaining raw data were normalized by using a cubic spline algorithm. This procedure was adapted from Hoshida et al. $^{23}$

\section{Statistical Analysis}

We compared men with both Gleason patterns $\leq 3$ ("Gleason $\leq 6$ ") with men who had both patterns $\geq 4$ ("Gleason $\geq 8$ ") to provide a sharp contrast between high and low Gleason scores, leaving out men with Gleason 7 for later testing (see below).

First, in each cohort, we performed a $t$ test for each of the 6,100 genes to distinguish low grade from high grade. We determined whether the top genes among those in the Swedish cohort were enriched among the those in the PHS by cross classifying genes according to whether or not they were in the top $5 \%, 10 \%, 15 \%, 20 \%$, or $25 \%$ of each, calculating a $\chi^{2}$ test statistic for each $2 \times 2$ table, and taking the largest of these; the $P$ value was calculated by permutation.

Pooling the cohorts, we ran a gene set enrichment analysis ${ }^{24,25}$ using 440 prespecified pathways from the Broad Institute's curated gene sets ${ }^{26}$ to identify pathways enriched in either the high- or low-grade tumors.

We used the prediction analysis of microarrays (PAM) R package ${ }^{27}$ to construct and validate a model predicting high-grade cancer. This method is an adaptation of a nearest neighbor classification method that considers models with different numbers of genes. First, we restricted our analysis to the Swedish data set (ie, the training data set). We selected an optimal model in the Swedish data by considering cross-validated prediction error and parsimony. Then we applied this model to the validation data set (PHS) and observed the misclassification. We visualized the differences in expression patterns between the two Gleason phenotypes by plotting individuals' scores along the first two principal components of the genes in this model, labeled by phenotype. We fit logistic regression models predicting lethal prostate cancer from these two principal components, among the Gleason $\leq 6$ and the Gleason $\geq 8$ separately to see whether overall differences in expression patterns correlated with lethal outcomes.

Finally, we calculated the model's predicted probabilities for poorly versus well-differentiated tumors for men with Gleason 7 tumors, who were not included in the training or validation sets. We sought to determine the model's ability to discriminate Gleason $4+3$ from $3+4$ and whether the molecular signature could improve prediction of lethal outcomes among men with Gleason 7 using logistic regression.

All analyses were performed with SAS 9.1 (SAS Institute, Cary, NC) and the $\mathrm{R}$ package. This study is compliant with ethical committees at the University of Örebro and the institutional review board of Partners HealthCare. 


\begin{tabular}{|c|c|c|c|c|}
\hline \multicolumn{5}{|c|}{$\begin{array}{l}\text { Table 1. Clinical Characteristics of Prostate Cancer Patients in the } \\
\text { Swedish and PHS Cohorts }\end{array}$} \\
\hline \multirow[b]{2}{*}{ Characteristic } & \multicolumn{2}{|c|}{$\begin{array}{l}\text { PHS Cohort } \\
(\mathrm{n}=109)\end{array}$} & \multicolumn{2}{|c|}{$\begin{array}{c}\text { Swedish } \\
\text { Cohort } \\
(n=358)\end{array}$} \\
\hline & No. & $\%$ & No. & $\%$ \\
\hline Years of diagnosis & \multicolumn{2}{|c|}{$1983-2003$} & \multicolumn{2}{|c|}{$1987-1999$} \\
\hline \multicolumn{5}{|l|}{ Gleason score } \\
\hline 5 & 0 & 0 & 3 & 1 \\
\hline 6 & 12 & 11 & 106 & 30 \\
\hline $3+4$ & 34 & 31 & 85 & 24 \\
\hline $4+3$ & 30 & 28 & 74 & 20 \\
\hline 8 & 18 & 16 & 22 & 6 \\
\hline 9 & 12 & 11 & 56 & 16 \\
\hline 10 & 3 & 3 & 12 & 3 \\
\hline \multicolumn{5}{|l|}{ Clinical outcomes } \\
\hline Lethal cases & 30 & 28 & 171 & 48 \\
\hline \multicolumn{5}{|l|}{ Stage } \\
\hline T1a-NO-MX & & & 110 & 31 \\
\hline T1b-NO-MX & & & 241 & 69 \\
\hline $\mathrm{T} 1 / \mathrm{T} 2$ & 70 & 65 & & \\
\hline T3 & 28 & 26 & & \\
\hline $\mathrm{T} 4 / \mathrm{N} 1 / \mathrm{M} 1$ & 10 & 9 & & \\
\hline Missing & 1 & & 7 & \\
\hline Age at diagnosis, years (mean $\pm \mathrm{SD}$ ) & & & 73 & \\
\hline
\end{tabular}

\section{RESULTS}

Clinical characteristics of the Swedish and PHS cohorts are provided in Table 1, and further details of each Gleason phenotype are provided in Table 2. All of the patients in the Swedish cohort were diagnosed from TURP or adenoma enucleation samples and thus were staged either T1a ( $<5 \%$ cancer) or T1b, depending on the proportion of the tissue that was cancerous. The majority of PHS patients $(65 \%)$ had $\mathrm{T} 1$ or $\mathrm{T} 2$ tumors.

To improve contrast of Gleason phenotypes in initial analyses, we compared tumors with Gleason score $\leq 6$ to those with Gleason score $\geq 8$. In the Swedish cohort, after Bonferroni correction for multiple comparisons, 107 genes remained significant at the family- wise 0.05 level (Appendix Table A1, online only) after 6,100 $t$ tests comparing low Gleason score with high Gleason score; 784 genes had a false discovery rate (FDR) less than 0.05 . In the PHS, a smaller data set of two genes were significant at the family-wise 0.05 level (Appendix Table A2, online only); 74 genes had an FDR less than 0.05. The top $10 \%$ of genes in the Swedish cohort were enriched in the top $10 \%$ of genes in the PHS cohort $(P<.001)$.

Pooling the cohorts, we applied a gene set enrichment analysis $(\text { GSEA })^{24,25}$ to identify pathways commonly enriched among highgrade or low-grade cancers. We identified 15 pathways from the GSEA database that were enriched among the high-grade tumors and three pathways that were enriched among the low-grade tumors with an FDR less than 0.10 (Table 3). The enriched pathways in the high-grade tumors are involved in the cell cycle, PI3K/AKT pathway, pyrimidine metabolism, and one-carbon folate, while pathways in the low-grade tumors were related to propanoate metabolism.

Separating the cohorts again, we built and tested a signature to predict high and low Gleason grades using PAM. We built the model in the Swedish data set (the training set) and estimated the level of misclassification of Gleason pattern using cross validation. The most parsimonious model that minimized misclassification contained 157 genes (Appendix Table A3, online only) and had an average misclassification rate of $17 \%$ of the two Gleason classes in the Swedish cohort (Appendix Fig A1, online only). We further examined the predictive ability of the genes in this set by measuring the area under the [concentration-time] curve (AUC) which was 0.91 (95\% CI, 0.87 to 0.95; Fig 1A). When our model from PAM was applied to the testing set (PHS data), the average misclassification rate was $16 \%$ in the two groups, and the AUC was 0.94 (95\% CI, 0.86 to 0.99 ; Fig 1B). When we built a signature using PAM on the PHS data and applied it to the Swedish cohort, the results for misclassification and AUC were similar (data not shown).

We examined the overall variability in expression of the 157 genes in the signature. Pooling the two cohorts, we calculated the first two principal components of the 157 genes in the model (Fig 2). The tumors with Gleason $\leq 6$ patterns seem to have fairly consistent values of the first principal component, suggesting more homogeneity in expression of genes. In contrast, those with Gleason $\geq 8$ tumors have a more varied expression pattern. We observed that among individuals with Gleason $\geq 8$, as they are further to the right of Figure 2 (more

\begin{tabular}{|c|c|c|c|c|c|c|}
\hline \multirow[b]{2}{*}{ Characteristic } & \multirow[b]{2}{*}{ Total No. of Patients } & \multicolumn{2}{|c|}{ Long-Term Survivors } & \multicolumn{2}{|c|}{$\begin{array}{l}\text { Patients With } \\
\text { Lethal Cancer }\end{array}$} & \multirow{2}{*}{$\begin{array}{c}\text { Age at Diagnosis } \\
\text { (mean years } \pm \text { SD) }\end{array}$} \\
\hline & & No. & $\%$ & No. & $\%$ & \\
\hline \multicolumn{7}{|l|}{ Swedish cohort } \\
\hline Gleason $\leq 6$ & 109 & 88 & 81 & 21 & 19 & $71.6 \pm 7$ \\
\hline Gleason $\geq 8$ & 89 & 14 & 16 & 75 & 84 & $74.6 \pm 7$ \\
\hline Gleason $3+4$ & 85 & 52 & 61 & 33 & 39 & $72.8 \pm 7$ \\
\hline Gleason $4+3$ & 74 & 33 & 45 & 41 & 55 & $75.3 \pm 7$ \\
\hline \multicolumn{7}{|l|}{ PHS cohort } \\
\hline Gleason $\leq 6$ & 12 & 12 & 100 & 0 & 0 & $64.4 \pm 4$ \\
\hline Gleason $\geq 8$ & 33 & 11 & 33 & 22 & 67 & $70.4 \pm 8$ \\
\hline Gleason 3 + 4 & 34 & 33 & 97 & 1 & 3 & $66.1 \pm 6$ \\
\hline Gleason $4+3$ & 30 & 23 & 77 & 7 & 23 & $66.4 \pm 7$ \\
\hline
\end{tabular}

Abbreviations: PHS, Physicians' Health Study; SD, standard deviation. 
Table 3. Gene Pathways Enriched in High-Grade (Gleason $\geq 8$ ) or Low-Grade (Gleason $\leq$ 6) Tumors, Based on Gene Set Enrichment Analysis Using Molecula Signature Databases From the Broad Institute

\begin{tabular}{|c|c|c|}
\hline Pathways Enriched in High-Grade Tumors & Pathway Description & Pathways Enriched in Low-Grade Tumors \\
\hline CELL_CYCLE_KEGG & & HSA00640_PROPANOATE_METABOLISM \\
\hline HSA04110_CELL_CYCLE & & PROPANOATE_METABOLISM \\
\hline G1_TO_S_CELL_CYCLE_REACTOME & & HSA00410_BETA_ALANINE_METABOLISM \\
\hline \multicolumn{3}{|l|}{ DNA_REPLICATION_REACTOME } \\
\hline PTDINSPATHWAY & $\begin{array}{l}\text { PI3K phosphorylate inositol rings of } \\
\text { phosphoinositide lipids, influencing vesicle } \\
\text { trafficking, cell proliferation, and migration }\end{array}$ & \\
\hline GSK3PATHWAY & $\begin{array}{l}\text { Bacterial lipopolysaccharide activates AKT to } \\
\text { promote the survival and activation of } \\
\text { macrophages and inhibits Gsk3-beta to promote } \\
\text { beta-catenin accumulation in the nucleus }\end{array}$ & \\
\hline ST_GA13_PATHWAY & $\begin{array}{l}\text { G-alpha- } 13 \text { influences the actin cytoskeleton and } \\
\text { activates protein kinase D, PI3K, and Pyk2 }\end{array}$ & \\
\hline \multicolumn{3}{|l|}{ PYRIMIDINE_METABOLISM } \\
\hline \multicolumn{3}{|l|}{ HSA00240_PYRIMIDINE_METABOLISM } \\
\hline \multicolumn{3}{|l|}{ ONE_CARBON_POOL_BY_FOLATE } \\
\hline \multicolumn{3}{|l|}{ HSA00670_ONE_CARBON_POOL_BY_FOLATE } \\
\hline \multicolumn{3}{|l|}{ MRNA_PROCESSING_REACTOME } \\
\hline EPOPATHWAY & $\begin{array}{l}\text { Erythropoietin, which activates the MAPK } \\
\text { pathway, stimulates erythrocyte production and } \\
\text { is an effective treatment for anemia }\end{array}$ & \\
\hline \multicolumn{3}{|l|}{ HSA04330_NOTCH_SIGNALING_PATHWAY } \\
\hline HSA04120_UBIQUITIN_MEDIATED_PROTEOLYSIS & & \\
\hline
\end{tabular}

NOTE. False discovery rate $<0.1$. Lines divide pathways into clusters based on large numbers of overlapping genes

Abbreviation: PI3K, phosphoinositide 3 kinase.

like the Gleason $\leq 6)$, their risk of lethal prostate cancer significantly decreases $(P=.03)$.

We then applied the 157-gene signature to the 159 men in the Swedish cohort and the 64 men in the PHS with Gleason 7 tumors to see whether those with Gleason $4+3$ would be more likely classified by the signature as Gleason $\geq 8$ than those with Gleason $3+4$. The predictive ability to discriminate $4+3$ from $3+4$ cancer was statistically significant but of modest magnitude; the AUC for this model was 0.60 (95\% CI, 0.53 to 0.68 ).

However, the 157-gene signature improved prediction of lethality among the men with Gleason 7 , a group with mixed predictive ability. We used logistic regression to predict prostate cancer-specific death among the Swedish men with Gleason 7; we included in the model the Gleason score $(4+3 v 3+4)$ and the estimated probability of being high grade from the 157-gene signature. We found that the probability of being high grade from the gene signature statistically significantly predicted lethal prostate cancer (odds ratio [OR], 1.46; $95 \%$ CI, 1.09 to 1.95 per $33 \%$ increase in predicted probability of being high grade); the gene signature provided a significant improvement over the model with Gleason score alone (likelihood ratio test $P=.01$ ). In an independent assessment in the PHS cohort, the OR was identical but the association was nonsignificant (OR, 1.44; 95\% CI, 0.57 to 3.68), reflecting the smaller sample size. Combining the men with Gleason 7 from the two cohorts, we found that the OR was 1.47 (95\% CI, 1.11 to 1.94 ) for a 33\% increase in the model prediction. This model, which included an indicator of Gleason score $(4+3 v$
A

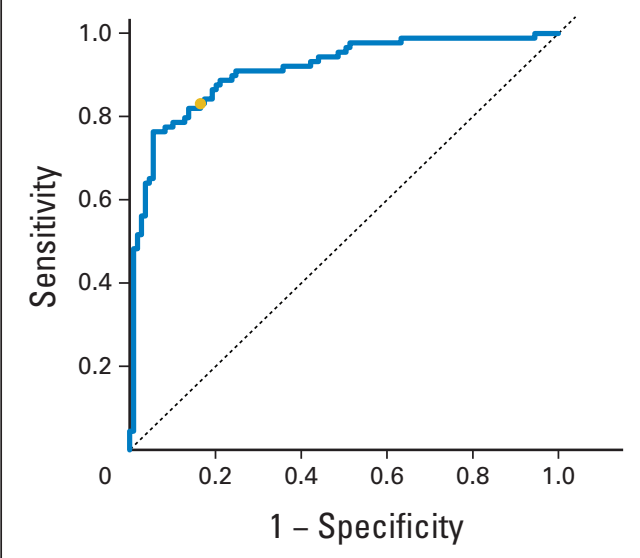

B

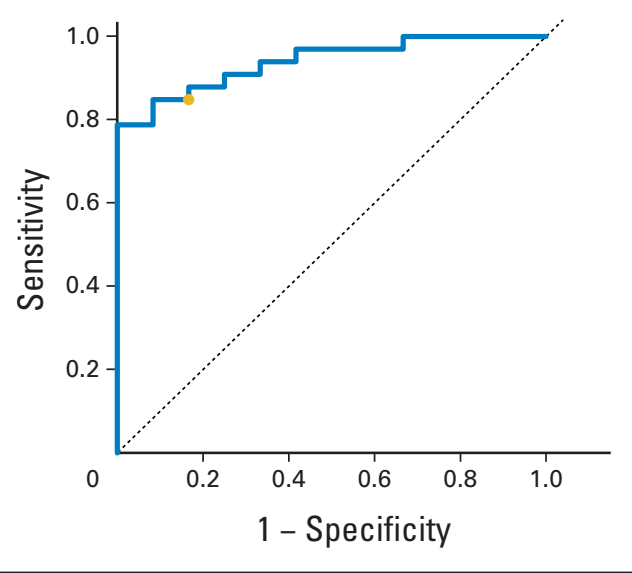

Fig 1. Receiver operating characteristic (ROC) curves for the 157-gene signature developed with prediction analysis of microarrays. (A) ROC curve for the model built in the Swedish cohort for Gleason $\leq$ 6 and Gleason $\geq 8$, applied to those same men. (B) ROC curve for the model built in the Swedish cohort applied to men in the Physicians' Health Study with Gleason $\leq$ 6 and Gleason $\geq 8$. In each plot, the gold dot is where misclassification rates are approximately equal in the two groups. 


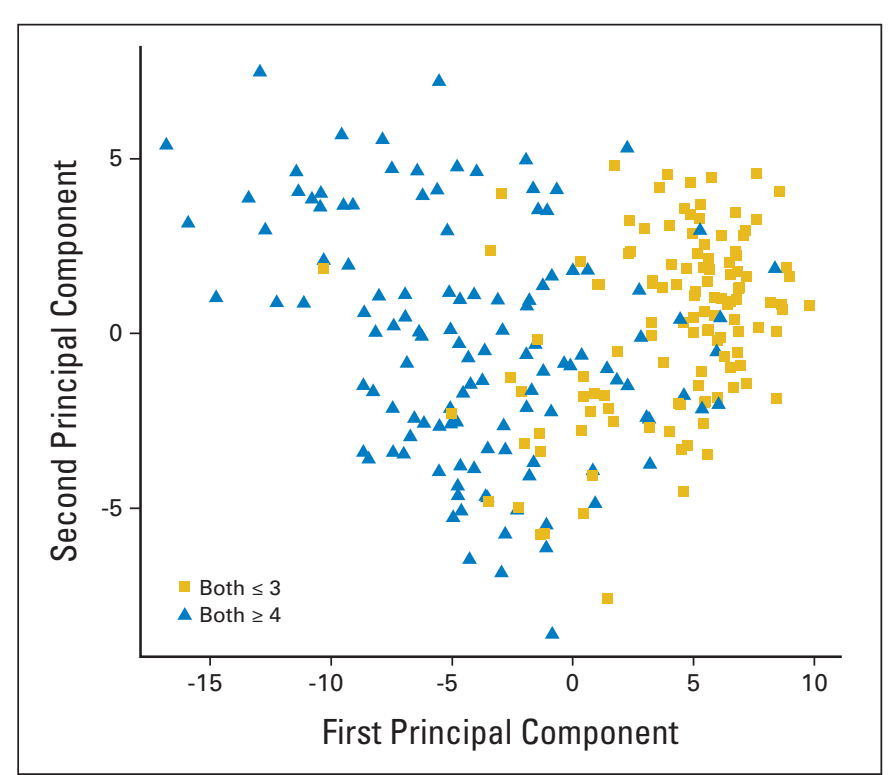

Fig 2. The first two principal components of the 157-gene model in the Swedish and Physicians' Health Study data sets, comparing men with Gleason $\leq 6$ (Both $\leq 3$ ) and men with Gleason $\geq 8$ (Both $\geq 4$ ).

$3+4)$, an indicator of cohort, and the predicted probabilities from our model, was significantly improved over a model with just Gleason score and cohort (likelihood ratio test $P=.006$ ). Adding age at diagnosis to the model does not change the predictive ability (OR, 1.48; $P=.006)$.

We compared the frequency of lethal cancers by tertiles of our predicted probability. One third of the men received predicted probabilities between 0 and 0.16 , one third between 0.16 and 0.73 , and one third between 0.73 and 1 . Twenty-nine percent of the men in the lowest tertile died of prostate cancer compared with $36 \%$ of the men in the middle tertile and $45 \%$ of the men in the upper tertile; thus, the difference in frequency of death between the lowest and highest tertiles was $16 \%$.

\section{DISCUSSION}

Gleason grade is one of the strongest clinical predictors of prostate cancer progression. Men with low-grade Gleason $\leq 6$ tumors, have a low metastatic potential, even in the absence of therapy ${ }^{28}$; in contrast, men with high-grade Gleason 8 to 10 tumors have a high likelihood of progression, even with curative therapies. There is mixed discrimination among the men diagnosed with Gleason 7 tumors, who represent a substantial proportion of prostate cancers diagnosed currently in the United States and other western countries. Improving risk prediction among patients with Gleason 7, as well as understanding the mechanisms leading to prostate tumor differentiation, is paramount to understanding this heterogeneous disease.

In this large study with long-term follow-up, we identified sets of genes that differentiate between low and high Gleason grade in a Swedish and a US cohort of men with prostate cancer. Additionally, we used a GSEA to identify the key pathways that go awry in the de-differentiation process in prostate cancer. Finally, we developed a Gleason signature that was significantly predictive of lethal prostate cancer among the men with Gleason 7, independent of $3+4$ or $4+3$ status. While this result warrants further study, it provides additional proof of principle for the utility of expression profiling in understanding the clinical heterogeneity of prostate cancer. This signature may have direct clinical application for men diagnosed with Gleason 7 tumors, the largest category of patients, and the one that poses the greatest challenges for treatment decision.

An additional finding was that, when examining the first two principal components of the genes in our 157-gene model, there was more homogeneity in patterns of expression among patients with Gleason $\leq 6$ than among those with Gleason $\geq 8$. This is consistent with the findings of True et $\mathrm{al}^{12}$ that Gleason pattern 3 alterations are fairly similar, while pattern 4 and 5 tumors are more diverse, even occasionally having features of pattern 3 . We consider this analogous to the first line of Tolstoy's Anna Karenina: "All happy families are alike; each unhappy family is unhappy in its own way." ${ }^{29}$ Minor loss of differentiation may occur in the same pathways and genes in most individuals, but greater loss of normal structure can occur in many different ways. We noted that as Gleason $\geq 8$ tumors looked more like Gleason $\leq 6$ tumors, the risk of lethal prostate cancer significantly decreased.

While we could reliably distinguish Gleason $\leq 6$ from Gleason $\geq 8$ in both our training and our test data sets, the signature did not discriminate well between Gleason $3+4$ and $4+3$. As we and others have shown, outcomes in the clinically heterogeneous category of Gleason 7 tumors can be further refined by determining the predominant Gleason score. ${ }^{8,30-32}$ The inability to identify a gene signature that distinguishes between Gleason $3+4$ and $4+3$ may be due to the way the tissues were collected - the Gleason grade of the exact cores used for mRNA extraction may not perfectly match the overall grade assigned to the patient. Therefore, the core from a Gleason score 7 could be Gleason grade 3, Gleason grade 4, or some combination of the two patterns.

In a previous examination of these datasets, we noted that the overall expression profiles for the Swedish and PHS samples differed substantially, most likely because of the types of specimens used (TURP for the Swedish cohort; 88\% RP for the PHS cohort). Our data suggest that the genes that predict Gleason score are robust regardless of the technique used for tissue collection, because we developed a signature in TURP samples and validated it in mostly RP specimens.

This study is larger than previous studies that address this question, includes centrally reviewed and standardized Gleason score measurements, and is able to examine the association of the developed signature with lethal prostate cancer. We examined only a subset of all known genes, so there could be many other genes that predict Gleason score. However, the 6,100 genes were selected specifically for possible involvement in prostate cancer, so they may capture a large proportion of the variation.

Our results provide many biologic hypotheses for genes and pathways that may underlie the differentiation of prostate cancer tissue. One pathway we identified through GSEA that involved the cell cycle was recently reported to be the module most strongly associated with Gleason in lymphoblastoid cell lines from patients with prostate cancer. ${ }^{33}$ Since Gleason score is a strong predictor of outcome, the pathways identified here may be important in disease progression as well.

The expression signature identified may enhance our understanding of the de-differentiation process of prostate tumors and may have clinical applications for men with Gleason 7 tumors, improving 
the prediction of lethal cancer and thereby guiding therapy decisions. The use of these prediction tools, or perhaps further refined versions, is likely to improve outcomes while reducing the overtreatment of indolent disease.

\section{AUTHORS' DISCLOSURES OF POTENTIAL CONFLICTS} OF INTEREST

Although all authors completed the disclosure declaration, the following author(s) indicated a financial or other interest that is relevant to the subject matter under consideration in this article. Certain relationships marked with a " $U$ " are those for which no compensation was received; those relationships marked with a " $C$ " were compensated. For a detailed description of the disclosure categories, or for more information about ASCO's conflict of interest policy, please refer to the Author Disclosure Declaration and the Disclosures of Potential Conflicts of Interest section in Information for Contributors.

Employment or Leadership Position: None Consultant or Advisory Role: Todd R. Golub, Foundation Medicine (C) Stock Ownership: Todd R. Golub, Foundation Medicine Honoraria: None Research Funding: None Expert Testimony: None Other Remuneration: None

\section{AUTHOR CONTRIBUTIONS}

Conception and design: Kathryn L. Penney, Jennifer A. Sinnott, Katja Fall, Yudi Pawitan, Jennifer R. Stark, Stephen Finn, Richard Flavin, Matthew L. Freedman, Sunita Setlur, Swen-Olof Andersson, Neil Martin, Philip W. Kantoff, Jan-Erik Johansson, Hans-Olov Adami, Mark A. Rubin, Massimo Loda, Todd R. Golub, Ove Andrén, Meir J. Stampfer, Lorelei A. Mucci

Financial support: Philip W. Kantoff, Jan-Erik Johansson, Todd R. Golub

Collection and assembly of data: Jennifer A. Sinnott, Katja Fall, Yudi Pawitan, Yujin Hoshida, Jennifer R. Stark, Michelangelo Fiorentino, Sven Perner, Stephen Finn, Stefano Calza, Richard Flavin, Sunita Setlur, Howard D. Sesso, Swen-Olof Andersson, Jan-Erik Johansson, Mark A. Rubin, Massimo Loda, Todd R. Golub, Ove Andrén, Meir J. Stampfer, Lorelei A. Mucci

Data analysis and interpretation: Kathryn L. Penney, Jennifer A. Sinnott, Yudi Pawitan, Peter Kraft, Michelangelo Fiorentino, Stefano Calza, Matthew L. Freedman, Howard D. Sesso, Neil Martin, Massimo Loda, Todd R. Golub, Meir J. Stampfer, Lorelei A. Mucci

Manuscript writing: All authors

Final approval of manuscript: All authors

\section{REFERENCES}

1. Stark JR, Mucci L, Rothman KJ, et al: Screening for prostate cancer remains controversial. BMJ 339:b3601, 2009

2. Schröder FH, Hugosson J, Roobol MJ, et al: Screening and prostate-cancer mortality in a randomized European study. N Engl J Med 360:13201328, 2009

3. American Cancer Society: American Cancer Society Cancer Facts and Figures 2010. Atlanta, GA, American Cancer Society, 2010

4. DeFrances CJ, Lucas CA, Buie VC, et al: 2006 National Hospital Discharge Survey. Natl Health Stat Report 5:1-20, 2008

5. Sboner A, Demichelis F, Calza S, et al: Molecular sampling of prostate cancer: A dilemma for predicting disease progression. BMC Med Genomics 3:8, 2010

6. Cheville JC, Karnes RJ, Therneau TM, et al: Gene panel model predictive of outcome in men at high risk of systemic progression and death from prostate cancer after radical retropubic prostatectomy. J Clin Oncol 26:3930-3936, 2008

7. Gleason DF: Classification of prostatic carcinomas. Cancer Chemother Rep 50:125-128, 1966

8. Stark JR, Perner S, Stampfer MJ, et al: Gleason score and lethal prostate cancer: Does $3+4=$ $4+3$ ? J Clin Oncol 27:3459-3464, 2009

9. Best CJ, Leiva IM, Chuaqui RF, et al: Molecular differentiation of high- and moderate-grade human prostate cancer by cDNA microarray analysis. Diagn Mol Pathol 12:63-70, 2003

10. Singh D, Febbo PG, Ross K, et al: Gene expression correlates of clinical prostate cancer behavior. Cancer Cell 1:203-209, 2002

11. Lapointe J, Li C, Higgins JP, et al: Gene expression profiling identifies clinically relevant subtypes of prostate cancer. Proc Natl Acad Sci U S A 101:811-816, 2004

12. True L, Coleman I, Hawley S, et al: A molecular correlate to the Gleason grading system for prostate adenocarcinoma. Proc Natl Acad Sci U S A 103:10991-10996, 2006

13. Bibikova M, Chudin E, Arsanjani A, et al: Expression signatures that correlated with Gleason score and relapse in prostate cancer. Genomics 89:666-672, 2007

14. Mendes A, Scott RJ, Moscato P: Microarrays: Identifying molecular portraits for prostate tumors with different Gleason patterns. Methods Mol Med 141:131-151, 2008

15. Tomlins SA, Mehra $R$, Rhodes DR, et al: Integrative molecular concept modeling of prostate cancer progression. Nat Genet 39:41-51, 2007

16. Andrén $O$, Fall K, Franzén L, et al: How well does the Gleason score predict prostate cancer death? A 20-year followup of a population based cohort in Sweden. J Urol 175:1337-1340, 2006

17. Aus G, Nordenskjöld K, Robinson D, et al: Prognostic factors and survival in node-positive (N1) prostate cancer: A prospective study based on data from a Swedish population-based cohort. Eur Urol 43:627-631, 2003

18. Johansson JE, Andrén O, Andersson SO, et al: Natural history of early, localized prostate cancer. JAMA 291:2713-2719, 2004

19. Final report on the aspirin component of the ongoing Physicians' Health Study: Steering Committee of the Physicians' Health Study Research Group. N Engl J Med 321:129-135, 1989

20. Hennekens $\mathrm{CH}$, Buring JE, Manson JE, et al: Lack of effect of long-term supplementation with beta carotene on the incidence of malignant neoplasms and cardiovascular disease. N Engl J Med 334:1145-1149, 1996

21. Setlur SR, Mertz KD, Hoshida $Y$, et al: Estrogen-dependent signaling in a molecularly distinct subclass of aggressive prostate cancer. J Natl Cancer Inst 100:815-825, 2008

22. Bibikova M, Talantov D, Chudin E, et al: Quantitative gene expression profiling in formalin-fixed, paraffin-embedded tissues using universal bead arrays. Am J Pathol 165:1799-1807, 2004
23. Hoshida $Y$, Villanueva $A$, Kobayashi $M$, et al: Gene expression in fixed tissues and outcome in hepatocellular carcinoma. N Engl J Med 359:19952004, 2008

24. Mootha VK, Lindgren CM, Eriksson KF, et al: PGC-1alpha-responsive genes involved in oxidative phosphorylation are coordinately downregulated in human diabetes. Nat Genet 34:267-273, 2003

25. Subramanian A, Tamayo $P$, Mootha VK, et al: Gene set enrichment analysis: A knowledge-based approach for interpreting genome-wide expression profiles. Proc Natl Acad Sci U S A 102:15545-15550, 2005

26. Broad Institute: Gene set enrichment analysis. http://www.broad.mit.edu/gsea/

27. Tibshirani $R$, Hastie $T$, Narasimhan $B$, et al: Diagnosis of multiple cancer types by shrunken centroids of gene expression. Proc Natl Acad Sci U S A 99:6567-6572, 2002

28. Albertsen PC, Hanley JA, Fine J: 20-year outcomes following conservative management of clinically localized prostate cancer. JAMA 293:20952101, 2005

29. Tolstoy L: Anna Karenina. New York, NY, Viking Penguin, 2001

30. Chan TY, Partin AW, Walsh PC, et al: Prognostic significance of Gleason score $3+4$ versus Gleason score $4+3$ tumor at radical prostatectomy. Urology 56:823-827, 2000

31. Makarov DV, Sanderson H, Partin AW, et al: Gleason score 7 prostate cancer on needle biopsy: Is the prognostic difference in Gleason scores $4+3$ and $3+4$ independent of the number of involved cores? J Urol 167:2440-2442, 2002

32. Rasiah KK, Stricker PD, Haynes AM, et al: Prognostic significance of Gleason pattern in patients with Gleason score 7 prostate carcinoma. Cancer 98:2560-2565, 2003

33. Wang $L$, Tang $H$, Thayanithy $V$, et al: Gene networks and microRNAs implicated in aggressive prostate cancer. Cancer Res 69:9490-9497, 2009 


\section{Focal Prostate Atrophic Lesions and risk of Lethal Prostate Cancer}

Davidsson $\mathrm{S}^{1}(\mathrm{MSc})^{*}$, Fiorentino $\mathrm{M}^{2,3}(\mathrm{MD})^{*}$, Andrén $\mathrm{O}^{1}(\mathrm{MD}, \mathrm{PhD})$, Fang $\mathrm{F}^{4,7}(\mathrm{MD}, \mathrm{PhD})$, Mucci LA ${ }^{4,5}(\mathrm{ScD})$, Varenhorst $\mathrm{E}^{6}(\mathrm{MD}, \mathrm{PhD})$, Fall $\mathrm{K}^{5,7}(\mathrm{MD}, \mathrm{PhD})^{* *}$, Stark $\mathrm{JR}^{1,3}(\mathrm{ScD})^{* *}$

* The authors contributed equally.

** The authors contributed equally.

${ }^{1}$ Department of Urology, Örebro University Hospital, Örebro, Sweden.

${ }^{2}$ Molecular Pathology Laboratory, Addarii Institute of Oncology, Department of HematologyOncology, University of Bologna, Bologna, Italy.

${ }^{3}$ Department of Pathology, Brigham and Women's Hospital and Adult Oncology, Dana-Faber Cancer Institute, Harvard Medical School, Boston, MA.

${ }^{4}$ Channing Laboratory, Brigham and Women's Hospital, Harvard Medical School, Boston, MA.

${ }^{5}$ Department of Epidemiology, Harvard School of Public Health, Boston, MA.

${ }^{6}$ Department of Urology, Linköping University Hospital, Linköping, Sweden.

${ }^{7}$ Department of Medical Epidemiology and Biostatistics, Karolinska Institutet, Stockholm, Sweden.

Contact information for corresponding author:

Sabina Davidsson, Department of Urology, Örebro University Hospital, 70185 Örebro, Sweden.

Tel: +46196026604; Fax: +46196026650.

E-mail address: sabina.davidsson@orebroll.se

Key words: Prostate adenocarcinoma, Chronic inflammation, Post-atrophic hyperplasia, Lethal prostate cancer 


\begin{abstract}
Purpose

To characterize prostate cancer (PCa) specimens with regard to inflammation and focal prostatic atrophy and to test whether the proposed precursor lesions in tumor adjacent tissue are associated with lethal PCa.
\end{abstract}

\title{
Materials and method
}

We investigated focal atrophy and inflammation with respect to PCa mortality in a cohort of Swedish men diagnosed with early PCa stage T1a-b tumors through transurethral resection of the prostate (TURP) between 1977 and 1999. We utilized an "extreme" case-control design by selecting as cases men who died of PCa within 10 years after diagnosis $(n=228)$. Men who survived more than 10 years after PCa diagnosis without any metastases $(n=387)$ served as controls. Slides were assessed for Gleason grade, type of inflammation, presence of prostatic intraepithelial neoplasia (PIN), and focal prostatic atrophy categorized as simple atrophy (SA), post-atrophic hyperplasia (PAH), partial atrophy, or simple atrophy with cyst formation. We used multivariable logistic regression to estimate odds ratios (ORs) and 95\% confidence intervals (CIs) for risk of lethal PCa.

\section{Results}

Chronic inflammation and PIN were more frequently observed in tumors with evidence of PAH but not SA. PAH was not associated with lethal PCa overall. However, in patients with moderate or severe chronic inflammation, the presence of PAH was associated with a not 
statistically significant two-fold (OR: 2.05; 95\% CI: 0.81-5.21) increased risk of PCa death compared to those without evidence of PAH.

\section{Conclusions}

Our data suggest that presence of PAH lesions in tumor adjacent tissue may have prognostic significance for PCa in the presence of inflammation.

\section{Introduction}

Accumulating evidence highlights the role of chronic or recurrent inflammation in human carcinogenesis [1-3]. Repeated tissue damage and regeneration in a microenvironment containing highly reactive oxygen and nitrogen species is thought to contribute to cancer development and progression. Chronic inflammation has also been hypothesized to influence prostate carcinogenesis, specifically. Both chronic and acute inflammation are commonly observed in prostate tumor specimens from prostatectomies, transurethral resections of the prostate (TURP), and biopsy samples [4-5]. Reactive molecules released by inflammatory cells, capable of interacting with DNA in the proliferating epithelium, may cause permanent genomic alterations such as rearrangements, deletions, and point mutations. In the prostate gland, chronic inflammation is associated with different types of focal glandular atrophy, especially post-atrophic hyperplasia (PAH) and simple atrophy (SA) [6-7]. These lesions, characterized by a highly proliferative epithelium are located in the peripheral zone of the gland, where prostate cancer most commonly develops [8-9]. The term proliferative inflammatory atrophy (PIA) has been proposed to designate proliferative glandular epithelium with morphologic appearance of PAH or SA in the presence of inflammation [6]. These 
lesions have been suggested as precursors of prostatic adenocarcinoma, either directly or indirectly via progression to intraepithelial neoplasia (PIN) [6, 10-12].

In support of the hypothesis, morphological studies have reported the transition from PIA to PIN and from PIA to cancer [12-14]. Proliferation in PAH lesions appears significantly greater than in benign prostatic epithelium and SA, but less than in PIN and prostate cancer [15]. Moreover, the association between chronic inflammation and PAH appears to be stronger than that with SA. Chromosome 8 gain has further been observed more frequently in PAH than in SA and PIN $[8,15-16]$. Chromosome 8 gain is considered to be a marker for poor prognosis in prostate adenocarcinoma [17].

No study to date has examined the role of proliferative atrophy as a predictor of lethal prostate cancer. In this population-based nested case-control study of men diagnosed with localized prostate cancer and followed up to 30 years after diagnosis, we evaluate chronic inflammation, type of focal atrophy, and PIN in adjacent tumor tissue as predictors of lethal prostate cancer.

\section{Material and methods}

The study is nested within a cohort of men with localized prostate cancer diagnosed in the Örebro and South East Health Care Regions of Sweden between 1977 and 1999 (earlier described in ref [18-20]). We initially identified a cohort of 1,367 men during the study period. Eligible patients were identified through population-based prostate cancer quality data-bases maintained in these regions. Included in the study are men who were diagnosed with incidental prostate cancer through TURP or adenoma enucleation, i.e. category T1a-b tumors. In accordance with standard treatment protocols, patients with early stage/localized 
prostate cancer were followed expectantly ("watchful waiting"). No PSA screening programs were in place at the time.

The study cohort was followed for cancer-specific and all-cause mortality until March 1, 2006, through record linkages to the Swedish Death Register and Migration Register, which provided date of death or migration respectively. Information on cause of death for each individual was obtained through a complete review of medical records by a study end-point committee. Deaths were classified as cancer specific when prostate cancer was the primary cause of death.

To maximize efficiency, we used a novel nested study design that included men who either died from PCa during follow up (lethal prostate cancer "cases", $\mathrm{n}=228$ ) or who survived at least 10 years following their diagnosis (indolent prostate cancer "controls", $n=387$ ). The study design excluded men with non-informative outcomes, namely those who died from other causes within 10 years after their cancer diagnosis $(\mathrm{N}=595)$. The study was approved by the Ethical Review Boards in Örebro and Linköping, Sweden.

\section{Tissue collection and evaluation}

Tumor tissue specimens were available from $92 \%(1,256)$ of the men with localized prostate cancer in the original cohort. All specimens were assessed to identify tumor areas and confirm cancer diagnosis. For the 615 patients selected for the case-control study of lethal prostate cancer-cases and indolent controls, H\&E slides for the corresponding paraffin-embedded formalin-fixed blocks were re-reviewed to confirm cancer status, Gleason score and other notable histopathological features by a single pathologist (M.F.) blinded to disease outcome and other clinical data. All slides were assessed for the presence and type of inflammation, either acute or chronic, according to cells of the inflammatory infiltrate. Chronic 
inflammation was further classified qualitatively as mild, moderate or severe. Focal prostate atrophy was characterized according to the atrophy classification, proposed 2006 by the Working Group for Histologic Classification of Prostate Atrophy Lesions (De Marzo 2006). The following four subtypes of atrophy are recognized: SA, simple atrophy with cyst formation (SACF), PAH, and partial atrophy. Table 1 describes the major characteristics of the four types of lesions.

\section{Statistical analyses}

Chi-square tests were used to evaluate associations between the types of focal atrophy and and presence of PIN and chronic inflammation, according to Gleason score. We used unconditional logistic regression to estimate odds ratios (ORs) and 95\% confidence intervals (CIs) for the outcome of lethal prostate cancer according to type of focal atrophy and degree of chronic inflammation. Statistical significance was determined by a Wald test for the dichotomous focal atrophy variables. For chronic inflammation analyses, we determined statistical significance by including a three-level ordinal variable for the categories of none, mild, and moderate/severe. In addition to unadjusted models, we also ran models adjusted for age at diagnosis (continuous), calendar year of diagnosis (1977-1982, 1983-1988, 1989-1993, and 1994-1998), and Gleason score at diagnosis in four categories (4-6, 7:3+4, 7:4+3, and 810). Analyses of the two major types of focal atrophy (SA and PAH) additionally controlled for the presence of chronic inflammation (none/mild vs. moderate/severe). We hypothesized that chronic inflammation and focal atrophy may act synergistically to influence prostate cancer progression. Thus, we specifically assessed the potential interactions between chronic inflammation and both SA and PAH on lethal prostate cancer. To assess statistical significance of the interaction, we used a 2 d.f. likelihood ratio test to compare unconditional logistic regression models that included age at diagnosis, calendar year of diagnosis, Gleason 
score category, and the product term of degree of chronic inflammation (none/mild vs. moderate/severe) with type of focal atrophy, to models without the product term. All statistical analyses were carried out using SAS Statistical Software version 9.2 (Cary, NC).

\section{Results}

We evaluated prostate specimens from 615 men who were diagnosed with incidental prostate cancer through TURP or adenoma enucleation. Clinical characteristics of the lethal prostate cancer cases and controls with indolent prostate cancer are shown in Table 2. Approximately half of the tumors evaluated were Gleason score 4-6 (47\%). Men diagnosed with T1a tumors comprised $41 \%$ of the study population, with the remainder being T1b.

The morphologic classification showed that SA was the most common type of focal atrophy in this material, identified in 365 of 615 men (59\%)(Table 2). PAH was present in one in five patients with similar distribution between lethal cases and indolent controls. PIN lesions were found less frequently (13\%), with a two-fold higher frequency in the lethal cases compared to controls with indolent disease (19\% and 10\%, respectively). PIN was more frequently observed in tumor specimens with evidence of PAH (22.4\% vs. $10.6 \%$; $\mathrm{p}<0.001)$, but the frequency of PIN did not vary according to the presence of SA (13.2\% in SA positive vs. $12.8 \%$ in SA negative; $p=0.90$ ).

Similar to earlier observations, chronic inflammation was a common feature; we identified chronic inflammation adjacent to the tumor in $74 \%$ of patients. The pattern of inflammation varied between tissue samples containing PAH lesions compared with those without PAH (Figure 1). Among patients with PAH, 93\% also had evidence of chronic inflammation, with $40 \%$ characterized as moderate or severe. In samples with no evidence of PAH, on the other 
hand, inflammation was present in $69 \%$ of the specimens, with only $23 \%$ consisting of the moderate/severe subtype.

Gleason score was inversely associated with the presence of both chronic and acute inflammation (Table 3). As Gleason score increased, chronic inflammation was less frequently observed in the tumors specimens $\left(\mathrm{p}_{\text {trend }}=0.04\right)$. Similarly, acute inflammation was more common in well-differentiated tumors (16.7\% in Gleason 4-6) compared to poorly differentiated tumors $(6.7 \%$ in Gleason $8-10)\left(\mathrm{p}_{\text {trend }}=0.01\right)$. We found no association between Gleason score and presence of SA ( $\left.\mathrm{p}_{\text {trend }}=0.15\right)$ or PAH $\left(\mathrm{p}_{\text {trend }}=0.85\right)$.

We also investigated whether chronic inflammation was associated with the risk of dying of prostate cancer (Table 4). In unadjusted analyses, we found no association between chronic inflammation and risk of death from prostate cancer (OR for moderate/severe inflammation vs. none; 1.10 (95\% CI: 0.70-1.70)). After adjustment for age at diagnosis, calendar year of diagnosis, and Gleason score, there was a suggestion of a positive association but it was not statistically significant. Controlling for clinical covariates, men with moderate/severe grade of inflammation were 1.5 times as likely to die of prostate cancer (95\% CI: 0.88-2.58) compared to men with no evidence of inflammation.

We found no overall association between either SA or PAH and lethal prostate cancer (Table 5). However, the association between PAH and lethal prostate cancer was modified by degree of chronic inflammation ( $\mathrm{p}$-interaction $=0.02$ ). Among those with moderate or severe chronic inflammation, the presence of PAH was associated with a not statistically significant two-fold increased risk of cancer-specific death compared to those without evidence of PAH (OR: 2.05; 95\% CI: 0.81-5.21). Among the subgroup of men with little or no chronic inflammation, 
we found no association between PAH and lethal prostate cancer. In contrast, there was no association observed between SA and lethal cancer among men with tumors in which chronic inflammation was absent or present.

We further investigated the overall association between PIN and prostate cancer death. The results revealed an $80 \%$ increased risk of dying from the disease among men with evidence of PIN adjacent to tumors compared to cases without adjacent PIN lesions when adjusted for age at diagnosis, calendar year of diagnosis, and Gleason score, and presence/absence of chronic inflammation (OR 1.81; 95\% CI: 1.01-3.25)(Table 5). We found no evidence of an interaction between chronic inflammation and PIN on lethal cancer.

\section{Discussion}

In line with earlier studies, our investigation revealed that chronic inflammation as well as focal atrophy lesions, are commonly found in tissue adjacent to prostate adenocarcinomas [21-22]. Our data further suggest that moderate or severe chronic inflammation, PAH in the presence of chronic inflammation, and PIN may be associated with an increased risk of prostate cancer-specific death. Despite the consistency in findings regarding the high frequency of chronic inflammation and focal glandular atrophy in prostate tumors, there is relatively little existing data on the associations between these features and cancer outcomes. One study of 65 patients did not find any difference in the incidence of newly identified prostate cancer at the time of re-biopsy according to the presence of focal atrophy [23]. Other studies have positively associated chronic inflammation and focal atrophy lesions with clinical covariates and biochemical recurrence [24-25]. This is to our knowledge the first large evaluation of chronic inflammation and proposed precancerous lesions (PAH and PIN) as determinants of prostate cancer-specific death. 
Somewhat surprisingly, we found that the presence of chronic inflammation was associated with more well-differentiated disease. In fact, the statistically nonsignificant positive association between chronic inflammation and prostate cancer-specific death became more pronounced after adjusting for Gleason score. Additional studies are needed to resolve the question if chronic inflammation has influence on prostate cancer progression. One possibility may be that only well differentiated prostate tissue has the ability to attract inflammatory cells. In this scenario additional carcinogenic mediators would be required to support tumor progression. Alternatively, the de-differentiation process within the tumor could replace any signs of previous inflammation in the area.

While our study did not directly address focal atrophy lesions or inflammation as a risk factor for prostate cancer, some observations in our study are consistent with the hypothesis that that chronic inflammation might influence normal prostate epithelia to transform into $\mathrm{PAH}$, which in turn may give rise to PIN as proposed by De Marzo et al [6]. First, as in previous studies [8, 15-16, 26], chronic inflammation was present in almost all specimens with PAH lesions and was more common and severe among men with PAH lesions than in men without evidence of PAH. Second, we found a correlation between the presences of PAH and PIN, potentially suggesting that PAH could be an early transformation in the prostate epithelium and that a subgroup of cells within the lesion has down-regulated tumor suppressor genes resulting in a more vulnerable state for genomic alterations. One of those genes is glutathione-S-transferase (GSTP1), which is presumed to protect cells from DNA damage caused by oxidative stress during episodes of inflammation [27]. Down-regulation of GSTP1 is also a common observation in PIN and prostate cancer [28-30]. 
Even if particular types of focal atrophy are, in fact, prostate cancer precursor lesions, we would not expect these lesions to predict prostate cancer aggressiveness unless aggressiveness was determined relatively early on in the carcinogenic process. A conceivable course of events may be that atrophy lesions in an environment of chronic inflammatory signals is stimulating the tumor to continue to grow and potentially metastasize. GSTP1 downregulation, along with TP53 mutations within the same subclone, may provide one potential mechanism through which focal atrophy lesions are associated with development of an aggressive prostate cancer subtype. Functional disorders of TP53 are general molecular features of many human neoplasms, including prostate cancer [15, 31]. Wang et al. identified a small subset of cells in PIA lesions that expressed mutated p53 but stained negative for GSTP1 [32], and Tsujimoto et al. found p53 mutations rates in PAH similar to the frequency of detection in PIN [33]. This evidence supports our hypothesis that a higher frequency of PAH lesions results in a higher frequency of cells sensitive for DNA alterations and that, within a micro milieu composed of reactive molecules, will enhance the risk for epithelial transformations characterized by replication advantages and aggressive potential.

We found that PAH lesions, but not SA lesions, were associated with PIN and prostate cancer death, suggesting that SA and PAH differ from each other not only morphologically, but also as they relate to prostate cancer development and progression. Previous studies have also identified similarities between PAH and PIN and between PAH and prostate cancer. Besides the fact that some atrophic cell lesions express low levels of GSTP1, a common finding in both PIN and prostate cancer, lower expression of the cyclin-dependent kinase inhibitor $\mathrm{p} 27^{\mathrm{Kip} 1}$ in the same lesions has also been reported [6]. $\mathrm{p} 27^{\mathrm{Kip} 1}$ has been observed to be downregulated at high frequencies in both PIN [34] and PCa [35]. Moreover, Shah et al. used FISH to evaluate chromosome 8 gain [15], which has been suggested as a common alteration in PIN 
and prostate cancer [36-37]. They found a higher amplification frequency of chromosome 8 in PAH lesions compared with SA lesions. Observations in prostatectomy specimens have also revealed a significant increase in nuclear proliferation gradually ranging from benign prostate (1.20\%), SA (2.67\%), PAH (3.62\%), PIN (6.14\%), to PCa (12\%) [15].

All 615 prostate cancer patients evaluated in the present study were diagnosed by TURP. While utilizing TURP specimens could be viewed as a limitation given that prostate cancer originates most frequently in the peripheral zone, approximately $25 \%$ of prostate adenocarcinomas are thought to develop within the transition zone [38]. In this study, we found a high proportion of large tumors encompassing both zones, and approximately $20 \%$ of the men in the original cohort of T1a-b tumors died from their prostate cancer. Interestingly, the frequency of focal atrophy lesions and PIN in the present study is also very similar to that of a large U.S.-based radical prostatectomy cohort (Stark et al. unpublished data). A strength of the study is the long follow-up allowing for a sufficient number of prostate cancer deaths to occur. Another unique feature is that all men were managed without initial treatment, which enables a study of the natural disease course.

In most cases, the cause of prostatic inflammation is obscure. However, viral and bacterial infections are well known to trigger inflammation and consequently inflammatory response. Due to the response infection induced inflammation may have the potential to increase the risk for prostate cancer initiation. Two large case-control studies revealed that presence of antibodies against Trichomonas vaginalis was positively associated with subsequent incidence of prostate cancer [39-40]. Furthermore, recent reports show that the bacterium Propionibacterium acnes was detected with high frequency in prostate tissue from men with prostate cancer but absent in other cancerous tissue biopsies [41-42]. Future studies should 
continue to investigate whether infectious agents are important in the etiology of prostate cancer.

In summary, our data suggest that men with PAH lesions in the presence of moderate or severe chronic inflammation at diagnosis were more than twice as likely to die of their prostate cancer. Only studies that evaluate focal atrophy in prostate tissue prior to cancer diagnosis can help to clarify whether these lesions predispose men to the development of prostate cancer. Nonetheless, our novel finding that men with moderate/severe chronic inflammation in presence of PAH have an increased risk of dying from prostate cancer, if confirmed, could suggest that strategies to reduce prostatic inflammation may improve survival for men with prostate cancer.

\section{Acknowledgments}

This project was supported in part by a Department of Defense Prostate Cancer Idea Development Award, PC060389 (PI Adami). JRS was supported by DF/HCC Prostate SPORE Career Development Award (PI Stark), NIH/NCI P50 CA90381. LAM was supported by the Prostate Cancer Foundation and KF was supported by Swedish Cancer Society, CAN 2006/1341 (PI Fall). 


\section{References}

1. Coussens LM,Werb Z: Inflammation and cancer. Nature 420(6917):860-7, 2002.

2. Balkwill F,Mantovani A: Inflammation and cancer: back to Virchow? Lancet 357(9255):539-45, 2001.

3. Mantovani A, et al.: Cancer-related inflammation. Nature 454(7203):436-44, 2008.

4. Nelson WG, De Marzo AM,Isaacs WB: Prostate cancer. N Engl J Med 349(4):366-81, 2003.

5. Blumenfeld W, Tucci S,Narayan P: Incidental lymphocytic prostatitis. Selective involvement with nonmalignant glands. Am J Surg Pathol 16(10):975-81, 1992.

6. De Marzo AM, et al.: Proliferative inflammatory atrophy of the prostate: implications for prostatic carcinogenesis. Am J Pathol 155(6):1985-92, 1999.

7. Aus G, et al.: EAU guidelines on prostate cancer. Eur Urol 48(4):546-51, 2005.

8. Ruska KM, Sauvageot J,Epstein JI: Histology and cellular kinetics of prostatic atrophy. Am J Surg Pathol 22(9):1073-7, 1998.

9. McNeal JE: Prostate cancer volume. Am J Surg Pathol 21(11):1392-3, 1997.

10. Palapattu GS, et al.: Prostate carcinogenesis and inflammation: emerging insights. Carcinogenesis 26(7):1170-81, 2005.

11. Platz EA,De Marzo AM: Epidemiology of inflammation and prostate cancer. J Urol 171(2 Pt 2):S36-40, 2004.

12. Putzi MJ,De Marzo AM: Morphologic transitions between proliferative inflammatory atrophy and high-grade prostatic intraepithelial neoplasia. Urology 56(5):828-32, 2000.

13. Wang W, Bergh A,Damber JE: Morphological transition of proliferative inflammatory atrophy to high-grade intraepithelial neoplasia and cancer in human prostate. Prostate 69(13):1378-86, 2009. 
14. De Marzo AM, Putzi MJ,Nelson WG: New concepts in the pathology of prostatic epithelial carcinogenesis. Urology 57(4 Suppl 1):103-14, 2001.

15. Shah R, et al.: Postatrophic hyperplasia of the prostate gland: neoplastic precursor or innocent bystander? Am J Pathol 158(5):1767-73, 2001.

16. Anton RC, et al.: Postatrophic hyperplasia of the prostate: lack of association with prostate cancer. Am J Surg Pathol 23(8):932-6, 1999.

17. Macoska JA, Trybus TM,Wojno KJ: 8p22 loss concurrent with 8c gain is associated with poor outcome in prostate cancer. Urology 55(5):776-82, 2000.

18. Andren O, et al.: How well does the Gleason score predict prostate cancer death? A 20-year followup of a population based cohort in Sweden. J Urol 175(4):1337-40, 2006.

19. Aus G, et al.: Survival in prostate carcinoma--outcomes from a prospective, population-based cohort of 8887 men with up to 15 years of follow-up: results from three countries in the population-based National Prostate Cancer Registry of Sweden. Cancer 103(5):943-51, 2005.

20. Johansson JE, et al.: Natural history of early, localized prostate cancer. JAMA 291(22):2713-9, 2004.

21. Gerstenbluth RE, et al.: Distribution of chronic prostatitis in radical prostatectomy specimens with up-regulation of bcl-2 in areas of inflammation. J Urol 167(5):226770, 2002.

22. Kaplan SA: Analysis of the inflammatory network in benign prostate hyperplasia and prostate cancer. J Urol 173(1):161, 2005.

23. Asimakopoulos AD, et al.: Significance of focal proliferative atrophy lesions in prostate biopsy cores that test negative for prostate carcinoma. Urol Oncol 2010. 
24. Alcover J, et al.: Prognostic value of IL-6 in localized prostatic cancer. Anticancer Res 30(10):4369-72, 2010.

25. Lin $\mathrm{HC}$, et al.: Influence of cytokine gene polymorphisms on prostate-specific antigen recurrence in prostate cancer after radical prostatectomy. Urol Int 83(4):463-70, 2009.

26. Billis A,Magna LA: Inflammatory atrophy of the prostate. Prevalence and significance. Arch Pathol Lab Med 127(7):840-4, 2003.

27. Kinzler KW,Vogelstein B: Cancer-susceptibility genes. Gatekeepers and caretakers. Nature 386(6627):761, 763, 1997.

28. Brooks JD, et al.: CG island methylation changes near the GSTP1 gene in prostatic intraepithelial neoplasia. Cancer Epidemiol Biomarkers Prev 7(6):531-6, 1998.

29. Lee WH, et al.: CG island methylation changes near the GSTP1 gene in prostatic carcinoma cells detected using the polymerase chain reaction: a new prostate cancer biomarker. Cancer Epidemiol Biomarkers Prev 6(6):443-50, 1997.

30. Lee WH, et al.: Cytidine methylation of regulatory sequences near the pi-class glutathione S-transferase gene accompanies human prostatic carcinogenesis. Proc Natl Acad Sci U S A 91(24):11733-7, 1994.

31. Wan Muhaizan WM, et al.: p53 and p21/WAF-1 overexpressions in prostatic adenocarcinoma. Malays J Pathol 28(2):93-9, 2006.

32. Wang W, Bergh A,Damber JE: Increased p53 immunoreactivity in proliferative inflammatory atrophy of prostate is related to focal acute inflammation. APMIS 117(3):185-95, 2009.

33. Tsujimoto Y, et al.: Postatrophic hyperplasia of the prostate in Japan: histologic and immunohistochemical features and p53 gene mutation analysis. Prostate 52(4):279-87, 2002. 
34. De Marzo AM, et al.: Stem cell features of benign and malignant prostate epithelial cells. J Urol 160(6 Pt 2):2381-92, 1998.

35. Yang RM, et al.: Low p27 expression predicts poor disease-free survival in patients with prostate cancer. J Urol 159(3):941-5, 1998.

36. Qian J, et al.: Chromosomal anomalies in prostatic intraepithelial neoplasia and carcinoma detected by fluorescence in situ hybridization. Cancer Res 55(22):5408-14, 1995.

37. Sato K, et al.: Clinical significance of alterations of chromosome 8 in high-grade, advanced, nonmetastatic prostate carcinoma. J Natl Cancer Inst 91(18):1574-80, 1999.

38. De Marzo AM, et al.: Pathological and molecular mechanisms of prostate carcinogenesis: implications for diagnosis, detection, prevention, and treatment. J Cell Biochem 91(3):459-77, 2004.

39. Stark JR, et al.: Prospective study of Trichomonas vaginalis infection and prostate cancer incidence and mortality: Physicians' Health Study. J Natl Cancer Inst 101(20):1406-11, 2009.

40. Sutcliffe S, et al.: Plasma antibodies against Trichomonas vaginalis and subsequent risk of prostate cancer. Cancer Epidemiol Biomarkers Prev 15(5):939-45, 2006.

41. Cohen RJ, et al.: Propionibacterium acnes associated with inflammation in radical prostatectomy specimens: a possible link to cancer evolution? J Urol 173(6):1969-74, 2005.

42. Fassi Fehri L, et al.: Prevalence of Propionibacterium acnes in diseased prostates and its inflammatory and transforming activity on prostate epithelial cells. Int J Med Microbiol 2010. 
Table 1. Key Histological Criteria of Focal Prostate Atrophy set up by Working Group Classification of Focal Prostate Atrophy Lesions

\begin{tabular}{|c|c|c|c|c|c|}
\hline & Normal & SA & PAH & SACF & Partial \\
\hline $\begin{array}{l}\text { Cytoplasm } \\
\text { amount }\end{array}$ & Abundant & Little, varible & Little, varible & Little & $\begin{array}{l}\text { More than other atrophy, } \\
\text { less than normal }\end{array}$ \\
\hline Cytoplasm color & Clear & Often dark & Often dark & Often clear & Clear \\
\hline Papillae & Abundant & None & None & None & None \\
\hline Gland size & Medium to large & $\begin{array}{c}\text { Similar to normal, but more } \\
\text { varible }\end{array}$ & Small & Medium to large & Small to medium \\
\hline Gland shape & Compound tubuloalveolar & $\begin{array}{l}\text { Similar to normal, less } \\
\text { complex }\end{array}$ & Mostly round & Round & Varible \\
\hline Gland packing & Well spaced & Similar to normal & Close & Close & Varible \\
\hline Inflam mation & Absent & Usually present & Usually present & Usually absent & Usually absent \\
\hline Morphology & & & & & \\
\hline
\end{tabular}




\begin{tabular}{|c|c|c|c|}
\hline & Overall (\%) & Indolent (\%) & Lethal (\%) \\
\hline Outcome & & $385(62.6)$ & $230(37.4)$ \\
\hline \multicolumn{4}{|c|}{ Acute inflammation } \\
\hline Yes & $84(13.7)$ & $56(14.5)$ & $28(12.2)$ \\
\hline No & $531(86.3)$ & $329(85.5)$ & $202(87.8)$ \\
\hline \multicolumn{4}{|c|}{ Chronic Inflammation grade } \\
\hline None & $164(26.7)$ & $97(25.2)$ & $67(29.1)$ \\
\hline Mild & $293(47.6)$ & $198(51.4)$ & $95(41.3)$ \\
\hline Moderate & $141(22.9)$ & $82(21.3)$ & $59(25.7)$ \\
\hline Severe & $17(2.8)$ & $8(2.1)$ & $9(3.9)$ \\
\hline \multicolumn{4}{|c|}{ Simple atrophy } \\
\hline Yes & $365(59.4)$ & $230(59.7)$ & $135(58.7)$ \\
\hline No & $250(40.6)$ & $155(40.3)$ & $95(41.3)$ \\
\hline \multicolumn{4}{|l|}{ PAH } \\
\hline Yes & $125(20.3)$ & $81(21.0)$ & $44(19.1)$ \\
\hline No & $490(79.7)$ & $304(79.0)$ & $186(80.9)$ \\
\hline \multicolumn{4}{|l|}{ SACF } \\
\hline Yes & $38(6.2)$ & $22(5.7)$ & $16(7.0)$ \\
\hline No & $577(93.8)$ & $363(94.3)$ & $214(93.0)$ \\
\hline \multicolumn{4}{|c|}{ Partial atrophy } \\
\hline Yes & $11(1.8)$ & $10(2.6)$ & $1(0.4)$ \\
\hline No & $604(98.2)$ & $375(97.4)$ & $229(99.6)$ \\
\hline \multicolumn{4}{|l|}{ PIN } \\
\hline Yes & $80(13.0)$ & $37(9.6)$ & $43(18.7)$ \\
\hline No & $535(87.0)$ & $348(90.4)$ & $187(81.3)$ \\
\hline \multicolumn{4}{|c|}{ Gleason score } \\
\hline $4-6$ & $288(46.8)$ & $240(62.3)$ & $48(20.9)$ \\
\hline $7: 3+4$ & $121(19.7)$ & $84(21.8)$ & 37 (16.1) \\
\hline $7: 4+3$ & $86(14.0)$ & $41(10.7)$ & 45 (19.6) \\
\hline $8-10$ & $120(19.5)$ & $20(5.2)$ & $100(43.5)$ \\
\hline \multicolumn{4}{|l|}{ T stage } \\
\hline T1a & $252(41.0)$ & $195(50.8)$ & $57(24.8)$ \\
\hline T1b & $362(59.0)$ & $189(49.2)$ & $173(75.2)$ \\
\hline
\end{tabular}




\begin{tabular}{|c|c|c|c|c|c|}
\hline & & $\begin{array}{c}\text { Gleason } \\
\text { score }\end{array}$ & & & \\
\hline & 4-6 (n,\%) & $7: 3+4(n, \%)$ & $7: 4+3(n, \%)$ & $8-10(n, \%)$ & \\
\hline \multicolumn{6}{|c|}{ Chronic inflammation } \\
\hline Yes & $218(75.7)$ & 93 (76.9) & 61 (70.9) & $79(65.8)$ & 0.04 \\
\hline \multicolumn{6}{|c|}{ Acute inflammation } \\
\hline Yes & $48(16.7)$ & $17(14.0)$ & $11(12.8)$ & $8(6.7)$ & 0.01 \\
\hline \multicolumn{6}{|c|}{ PAH } \\
\hline Yes & $53(18.4)$ & $31(25.6)$ & $19(22.1)$ & $22(18.3)$ & 0.85 \\
\hline \multicolumn{6}{|l|}{ SA } \\
\hline Yes & $179(62.2)$ & $71(58.7)$ & $49(57.0)$ & $66(55.0)$ & 0.15 \\
\hline \multicolumn{6}{|l|}{ PIN } \\
\hline Yes & $18(6.3)$ & $20(16.5)$ & $19(22.1)$ & $23(19.2)$ & $<0.0001$ \\
\hline
\end{tabular}

\begin{tabular}{|c|c|c|c|c|}
\hline & Indolent (\%) & Lethal (\%) & OR $^{1}(95 \% \mathrm{Cl})$ & $\mathrm{OR}^{2}(95 \% \mathrm{Cl})$ \\
\hline \multicolumn{5}{|c|}{ Chronic inflammation } \\
\hline No & $97(25.2)$ & $66(29.1)$ & Ref & Ref \\
\hline Mild & $198(51.4)$ & $95(41.3)$ & $\begin{array}{l}0.70(0.47- \\
1.03)\end{array}$ & $0.94(0.58-1.54)$ \\
\hline Moderate/Severe & $90(23.4)$ & $68(29.6)$ & $\begin{array}{l}1.10(0.70- \\
1.70)\end{array}$ & $1.51(0.88-2.58)$ \\
\hline \multicolumn{5}{|c|}{$\begin{array}{l}\text { OR }^{1} \text { unadjusted; } \mathrm{OR}^{2} \text { adjusted for age at diagnosis, calendar period of diagnosis (1977- } \\
1982,1983-1988,1989-1993 \text {, and 1994-1998), and Gleason categories (4-6, 7:3+4, } \\
7: 4+3 \text {, and 8-10) }\end{array}$} \\
\hline
\end{tabular}


Table 5. Odds ratios (ORs) and 95\% confidence intervals $(\mathrm{Cl})$ of lethal prostate cancer by type of focal atrophy, Swedish Watchful Waiting Cohort, 1977-2006

\begin{tabular}{|c|c|c|}
\hline & No PAH & PAH \\
\hline Overall $^{*}$ & 1.00 (Ref) & $0.84(0.51-1.38)$ \\
\hline \multicolumn{3}{|c|}{ Stratified by Inflammation ${ }^{\star \star}, \S$} \\
\hline No/Mild & 1.00 (Ref) & $0.73(0.36-1.47)$ \\
\hline \multirow[t]{2}{*}{ Moderate/Severe } & 1.00 (Ref) & $2.05(0.81-5.21)$ \\
\hline & No SA & SA \\
\hline Overall* & 1.00 (Ref) & $1.09(0.73-1.65)$ \\
\hline \multicolumn{3}{|c|}{ Stratified by Inflammation $^{\star \star,} \S \S$} \\
\hline No/Mild & 1.00 (Ref) & $1.25(0.78-1.47)$ \\
\hline \multirow[t]{2}{*}{ Moderate/Severe } & 1.00 (Ref) & $0.54(0.23-1.32)$ \\
\hline & No PIN & PIN \\
\hline Overall* & 1.00 (Ref) & $1.81(1.01-3.25)$ \\
\hline \multicolumn{3}{|c|}{ Stratified by Inflammation $^{\star \star}, \S \S \S$} \\
\hline No/Mild & 1.00 (Ref) & $1.63(0.84-3.19)$ \\
\hline Moderate/Severe & 1.00 (Ref) & $3.23(0.78-13.32)$ \\
\hline \multicolumn{3}{|c|}{$\begin{array}{l}\text { *Adjusted for age at diagnosis, calendar year of diagnosis, Gleason score, and } \\
\text { presence/absence of chronic inflammation }\end{array}$} \\
\hline \multicolumn{3}{|c|}{${ }^{\star \star}$ Adjusted for age at diagnosis, calendar year of diagnosis, and Gleason score } \\
\hline \multicolumn{3}{|c|}{$\S p$-interaction for $\mathrm{PAH}$ and chronic inflammation $=0.02$} \\
\hline \multicolumn{3}{|c|}{$\S \S p$-interaction for SA and chronic inflammation $=0.34$} \\
\hline \multicolumn{3}{|c|}{$\S \S \S p$-interaction for PIN and chronic inflammation $=0.58$} \\
\hline
\end{tabular}




\section{Mara Meyer \\ Abstract for AACR Advances in Prostate Cancer conference \\ NOVEMBER 16, 2008}

\section{Genetic variation in $R N A S E L$ and prostate cancer risk}

Background: Emerging experimental and human evidence point to a role for inflammation and infection in prostate carcinogenesis and disease progression. Variation in genes contributing to the host immune response may mediate the inflammatory response to infectious agents, and thereby influence prostate cancer progression. RNASEL at chromosome 1q25 encodes ribonuclease $\mathrm{L}$, part of the interferon-mediated immune response to viral infection. The $R 462 Q$ variant has been studied in several epidemiological studies, although the results have been mixed. We conducted a large, prospective study of this and other variants across RNASEL in relation to prostate cancer risk and progression within the Physicians' Health Study.

Methods: The nested case-control design included 1021 cases diagnosed between 1982 and 2000, and 1082 controls matched on age and follow-up time. We genotyped eleven haplotype single nucleotide polymorphisms (SNPs) in RNASEL selected using web-based Tagger to characterize variation across the gene (average $\mathrm{r}^{2}=1.00$ ). Co-dominant genetic models adjusted for age and follow-up time assessed the relationship between each SNP and total prostate cancer incidence, as well as risk of prostate cancer diagnosed at advanced stage (T3/T4/N1/M1), or with high Gleason grade (Gleason 7 or greater). We further explored associations of the RNASEL SNPs with plasma inflammatory biomarkers interleukin-6 (IL-6), C-reactive protein (CRP), and tumor necrosis factor receptor 2 (TNFR2) by linear regression models.

Results: We found no significant association between any of the 11 SNPs in RNASEL and total prostate cancer risk. However, variant rs12757998 was associated with significantly increased risk of Gleason $\geq 7$ tumors (OR: $1.75,95 \% \mathrm{CI}$ : 1.10-2.80) when compared to the homozygous dominant genotype. This SNP was also correlated with $25 \%$ higher circulating levels of IL-6 $(\mathrm{p}=0.07)$ and $43 \%$ higher levels of CRP ( $\mathrm{p}=0.02)$. The variant form of a second SNP, rs533259, was also associated with $89 \%$ higher circulating levels of CRP $(\mathrm{p}=0.06)$, but not cancer risk. Conversely, variant rs682585 was significantly associated with reduced risk of advanced disease (OR: 0.62, 95\% CI: 0.40-0.94) when compared to the homozygous dominant genotype. None of the SNPs analyzed were associated with circulating levels of TNFR2. We found no significant associations with previously reported missense variants $R 462 Q$ (rs486907) and D541E (rs627928) and total prostate cancer or aggressive disease, defined by disease stage or tumor grade.

Discussion: Our results suggest genetic variation in RNASEL is associated with prostate cancer progression. The effect may be mediated by circulating levels of inflammatory biomarkers, as suggested by elevated levels of CRP and IL-6 with the variant form of certain SNPs. 
Trichomonas vaginalis infection and prostate cancer incidence and mortality: A prospective study in the Physicians'

Health Study. Jennifer R. Stark,1 Gregory Judson,1 John F. Alderete,2 Siobhan Sutcliffe, 3 Vasanthakrishna Mundodi, 2 Ashwini S. Kucknoor,2

Edward L. Giovannucci, 1 Elizabeth A. Platz,4 Katja Fall, 5 Tobias Kurth, 1 Jing Ma,6 Meir J. Stampfer, 1 Lorelei A. Mucci1. 1 Harvard School of Public Health, Boston, MA; 2Washington State University, Pullman, WA; 3 Washington University, St. Louis, MO; 4Johns Hopkins University, Baltimore, MD; 5Karolinska Institutet, Stockholm, Sweden; 6Brigham and Women's Hospital, Boston, MA.

Background: Several inflammation-related factors have been implicated in prostate cancer risk and progression, but the origin of inflammation is unclear. Infections are one possible source, but studies of specific infections have been largely inconclusive. A recent prospective study found that antibody seropositivity against Trichomonas vaginalis was positively associated with subsequent incidence of prostate cancer. This parasitic protozoan has received relatively little attention despite being the most common non-viral sexually transmitted infection. We sought to further explore and extend this hypothesis in an independent population, both for prostate cancer incidence as well as progression.

Methods: We conducted a prospective case-control study nested within the Physicians' Health Study that included 673 prostate cancer cases and 673 individually matched controls. T. vaginalis antibody serostatus was assessed by an ELISA that detects IgG antibodies against purified, recombinant $\mathrm{T}$. vaginalis -actinin protein.We used conditional logistic regression for analyses of total prostate cancer incidence and Cox proportional hazards models to estimate hazard ratios for lethal prostate cancer (prostate cancer-specific death or development of bony metastases). Results: The seroprevalence of $T$. vaginalis infection was $21 \%$ in controls and $25 \%$ in cases. Among cases, the average time between blood draw and prostate cancer diagnosis was 9.3 years (range 0.3 years - 17.9 years). Though not statistically significant, the magnitude of the association between $\mathrm{T}$. vaginalis seropositivity and overall prostate cancer risk (OR: $1.23 ; 95 \% \mathrm{Cl}: 0.94,1.61$ ) was similar to the original study, which observed a $43 \%$ increased risk. Further, seropositive men had a 2.2 -fold increase in risk of extraprostatic disease $(95 \% \mathrm{Cl}: 1.08,4.37)$ and a $2.7-$ fold greater risk of lethal prostate cancer $(95 \% \mathrm{Cl}$ : $1.37,5.28 ; 39$ cases developed bony metastases or died of prostate cancer). Time-to event analyses included 7,776 person-years of follow-up and showed that, compared to seronegative cases, cases with serologic evidence of infection prior to cancer diagnosis had a $50 \%$ greater rate of progression to lethal prostate cancer $(95 \% \mathrm{Cl}$ : 1.01, 2.16).

Conclusions: In this large prospective study, we observed a modest association between anti-T. vaginalis antibodies and overall prostate cancer risk and found that $T$. vaginalis infection was principally associated with clinically relevant, potentially lethal disease. If our findings are confirmed, T. vaginalis infection may represent a common risk factor for which chemoprevention could reduce burden of aggressive prostate cancer. 


\section{Post-Atrophic Hyperplasia Lesions and Prostate Cancer Survival}

Jennifer R. Stark, Michelangelo Fiorentino, Richard J. Flavin, Whitney Hendrickson, Katja

Fall, Elizabeth A. Platz, Angelo De Marzo, Massimo Loda, Meir J. Stampfer, Edward L.

Giovannucci, Lorelei A. Mucci

An understanding of the role of inflammatory lesions and focal atrophy in prostate cancer survival could help to identify patients for whom aggressive treatment is most appropriate, as well as provide insights into the underlying mechanisms of carcinogenesis, opening up avenues for both primary and secondary prevention. We are currently evaluating 1,500 prostatectomy specimens from the Health Professionals' Follow-up Study and the Physicians' Health Study diagnosed from $1982-2009$ for four subtypes of focal atrophy lesions: simple atrophy, simple atrophy with cyst formation (SACF), postatrophic hyperplasia (PAH), and partial atrophy. Cases are concurrently being evaluated for presence of acute inflammation and degree of chronic inflammation (absent, mild, moderate, or severe). To date, 310 cases have been evaluated. Simple atrophy was present in $72 \%$, SACF in $15 \%$ of cases, $\mathrm{PAH}$ in $25 \%$, and partial atrophy in $3 \%$ of the cases. Evidence of moderate or severe chronic inflammation was present in $25 \%$ of the specimens, while mild chronic inflammation was found in $59 \%$. Acute inflammation was present in $24 \%$ of the specimens. Once complete data from the focal atrophy/inflammation evaluation become available, we will also relate presence of focal atrophic lesions and extent of inflammation to Gleason score, tumor proliferation, apoptosis, and angiogenesis in the adjacent tumor. We will also undertake a time-to-event analysis of the 1,500 cases ( $n=160$ lethal events) to determine if the presence of atrophic lesions are associated with disease progression or death, as well as determine if evidence of atrophic lesions at prostatectomy add to the predictive ability of models including data on Gleason score, age, and tumor stage. 


\section{Focal Prostate Atrophic Lesions and Risk of Lethal Prostate Cancer}

Sabina Davidsson, Michelangelo Fiorentino, Ove Andrén, Fang Fang, Lorelei A Mucci, Eberhart Varenhorst, Katja Fall and Jennifer Rider Stark

\section{Background}

Repeated tissue damage and regeneration in a highly reactive microenvironment may contribute to cancer development and progression, including prostate cancer. Chronic inflammation has also been hypothesized to influence prostate carcinogenesis and is often associated with focal glandular atrophy, especially post-atrophic hyperplasia (PAH) and simple atrophy (SA). The term proliferative inflammatory atrophy (PIA) has been proposed to designate proliferative glandular epithelium with morphologic appearance of PAH or SA occurring in the presence of inflammation. It has been hypothesized that these lesions may represent a precursor of prostate cancer (PCa). It is unknown whether the presence of PIA lesions is associated with the risk of dying of $\mathrm{PCa}$.

\section{Design}

We investigated PIA and cancer mortality in a cohort of Swedish men diagnosed through TURP between 1977-99 with early PCa stage T1a-b tumors. We utilized an "extreme" casecontrol design by selecting as cases men who died of PCa within 10 years after diagnosis $(n=228)$ and as controls men who survived more than 10 years after PCa diagnosis without any metastases $(n=387)$. Slides were assessed for Gleason grade, presence and type of inflammation. Focal prostate atrophy was characterized according to a new atrophic classification. We used multivariable logistic regression to calculate odds ratios (OR) and 95\% Confidence Intervals (CI)

\section{Results}

We identified chronic inflammation in $74 \%$ of the specimens. SA (59.4\%) and PAH (20.3\%) were the two most common atrophy lesions present. We found that HGPIN was more frequently observed in tumors with evidence of PAH (22\% PAH positive vs. $11 \% \mathrm{PAH}$ negative; $\mathrm{p}<0.001$ ). We found no overall association between either SA or PAH and lethal PCa. However, the association between PAH and lethal PCa was modified by degree of chronic inflammation ( $\mathrm{p}$-interaction $=0.02$ ). In patients with moderate or severe chronic inflammation the presence of PAH was associated with a 2-fold increased risk of PCa death compared to those without evidence of PAH (OR: 2.05; 95\% CI: 0.81-5.21).

\section{Conclusions}

This study provides evidence that PAH lesions may have prognostic significance for PCa in the presence of inflammation. Chronic inflammation was a common feature in men with PCa and present in almost all specimens with evidence of PAH. HGPIN was more frequently observed in tumors with PAH present. A higher frequency of PAH lesions in an environment of chronic inflammation may result in more cells sensitive to DNA alterations, enhancing the potential for epithelial transformations that may lead to lethal PCa. 